\title{
Agricultura de riego y tradiciones en el valle del Colca
}

\author{
Román Robles Mendoza \\ hermanovallejo@hotmail.com \\ Departamento de Antropología, UNMSM
}

\begin{abstract}
Resumen
Desde tiempos prehispánicos, la economía de las sociedades andinas ha estado sustentada en la agricultura y la ganadería. El mundo rural de hoy sigue siendo heredera de esta antigua estrategia de vida, donde el sistema de producción ha experimentado pocos cambios en más de cinco siglos. En el presente trabajo hacemos una revisión general de la actividad agrícola bajo riego y del pastoreo, como estrategias para la sobrevivencia del campesinado, en una región significativa del país como es el valle del Colca en Arequipa. Utilizando informaciones recogidas en trabajos de campo, datos oficiales de las agencias del sector público y de la bibliografía existente, presentamos las características básicas de la agricultura de riego en los pueblos del valle, enfatizando el tema de escasez del recurso hídrico, indispensable para la agricultura de hoy y del permanente mantenimiento de la infraestructura hidráulica. Se complementa el estudio con la descripción de antiguas tradiciones, donde la sacralización de la naturaleza de su entorno forma parte del universo ideológico del campesinado, y de los recientes intentos por modernizar el sistema de riego para apoyar el desarrollo de la producción agrícola.
\end{abstract}

Palabras clave: Agricultura, riego, andenería, ritualidad, campesinado.

\begin{abstract}
Since prehispanic times, the economy of the Andean societies has been based on agriculture and livestock. The rural world of today remains the heir of this ancient strategy of life, where the production system has changed little in over five centuries. In this paper we make a general review of irrigated farming and grazing, like strategies for the survival of the peasantry, in a significant region of the country as the Colca Valley in Arequipa. Using information gathered in field work, official data from public sector agencies and the existing literature, we present the basic characteristics of irrigated agriculture in the valley towns, emphasizing the issue of scarcity of water resources, essential for agriculture today and permanent
\end{abstract}


maintenance of water infrastructure. It complements the study with the description of ancient traditions, where the sacredness of the nature of your environment is part of the ideological universe of the peasantry, and recent attempts to modernize the irrigation system to support the development of agricultural production.

Keywords: Agriculture, irrigation, terrace cultivation, ritual, peasantry.

\section{Introducción}

Los temas que enfocan los problemas del mundo rural tienen muy pocos seguidores en las investigaciones científico sociales de estos tiempos. Otras áreas del conocimiento como los movimientos contestatarios de las regiones y de las etnias nativas, los asuntos derivados de la explotación de recursos naturales como el petróleo y el gas natural, los problemas medio ambientales, la ciudadanía, los temas políticos nacionales y del subcontinente, modernización de la realidad urbana, acaparan mayores espacios en las preocupaciones de los estudiosos de nuestros días. Sin embargo, en el escenario rural del país, existe una amplia gama de temas que requieren de permanente observación, interpretación y análisis. Una parte de esos temas tienen que ver con la realidad campesina dedicada a la agricultura, la ganadería, la artesanía, la industria y nuevas actividades como el transporte, el turismo, las comunicaciones, en un tiempo donde la distancia tradicional del campo a la ciudad se ha acortado al ritmo de la modernización y la globalización de la economía y la cultura en que vivimos.

En este trabajo nos ocupamos de la agricultura de riego en una cuenca interandina del Colca $^{1}$ en el departamento de Arequipa, que siendo una región casi similar a otras cuencas de la sierra peruana, tiene sus propias particularidades. Lo abordamos desde una visión de conjunto, de una región que guarda unidad económica, social y cultural, por estar dentro de un pequeño espacio geográfico de varios pisos ecológicos. Aun cuando los grupos humanos que la han habitado y la habitan se diferencian por dos especialidades de vida económica, la agricultura y el pastoreo, desde antes han interactuado y lo siguen haciendo para complementar sus estilos de vida. Los antiguos intercambios de trueque producto-producto entre pastores de altura y agricultores del valle, sustituido hoy por las ferias y exposiciones de productos que se organizan en distintas localidades, confirma la continuidad de la unidad social, cultural y económica de los pueblos del valle del Colca.

Prestamos mayor atención a la actividad agrícola de irrigación que practican los campesinos de las comunidades, a quienes se les conoce como usuarios, en el sistema de organización del riego. En estos pueblos de economía agrícola cultivan todo lo que han aprendido a consumir desde antiguo, en sus terrenos planos y en aquellas tierras que sus antepasados han ampliado mediante la construcción de miles de andenes a lo largo y ancho del valle. Para hacer producir la tierra utilizan toda una red de canales antiguos y modernos, clasificados en canales principales, secundarios y ramales de enlace a las parcelas y de otra cantidad de reservorios para controlar las aguas de riego. Revisamos también los rasgos de la tecnología que usan para cultivar, las innovaciones que introducen y el destino de los productos que cosechan. En la parte final del trabajo reseñamos las tradiciones vivas de la religión de origen prehispánico, que en este valle se manifiesta en una serie de rituales y representaciones espirituales, históricamente construidas, para conjurar la escasez del recurso hídrico, apelando al poder de los dioses montaña de la región y de los espíritus de sus antepasados.

1 Distintos estudios coinciden en que el nombre de Colca viene de la palabra quechua que designa a los depósitos prehispánicos de alimentos construidos en los acantilados de Tuti, situados a $4.000 \mathrm{msnm}$. 


\section{El Valle del Colca en el sur andino}

Situado al norte de la ciudad de Arequipa, a una distancia de $161 \mathrm{~km}$, se ubica el valle del Colca. Es la parte sierra de la provincia de Caylloma, cuya capital es Chivay, circunscripción política que abarca desde los desiertos de Pedregal y Sihuas en la costa, y se eleva hasta los $5597 \mathrm{msnm}$ en la emblemática cordillera nevada del Mismi. Por sus características especiales, el valle del Colca es la más densamente poblada en esta provincia, por la concentración demográfica en sus dieciséis asentamientos que existen hoy a lo largo de los $140 \mathrm{~km}$ de extensión, de Este a Oeste, entre Tisco y Tapay.

Sobre el valle del Colca se han hecho diversos estudios desde diferentes líneas profesionales. Probablemente, los estudios de la fase colonial han merecido dedicación privilegiada por la abundancia de materiales de información en los archivos. El historiador Pease (1977) ha compilado trabajos relativos a la etnia de los collaguas del valle en dos volúmenes $^{2}$ y otros como Cock (1977) han estudiado acerca de los curacas y la visita de Toledo a la región de Arequipa. Trabajos arqueológicos e históricos sobre andenería, agricultura y sistema de riego en las poblaciones del Colca han sido abordados por Denevan (1986) y Treacy (1994). Valderrama y Escalante (1988) dedicaron un excelente trabajo etnográfico sobre riego y ritualidad en Yanque ${ }^{3}$. Tord (1984) ha estudiado el tema de los templos coloniales en los pueblos del valle; Ráez (2002) ha hecho un recuento de las fiestas, músicas y danzas que se practican en estos pueblos. Estos son algunos de los más importantes estudios publicados sobre esta región, pero hay abundante bibliografía sobre distintos aspectos del valle. Desde los años setentas, cuando se iniciaron los trabajos del Proyecto Majes $^{4}$ se incrementaron los estudios y el valle tomó notoriedad, no sólo por su belleza paisajística, sino también por su importancia productiva agropecuaria. Casi cuarenta años más tarde, el valle es un punto de referencia para nacionales y extranjeros que desean conocer a uno de los cañones más profundos del mundo (4160 m); presenciar el vuelo de los cóndores que salen planeando de sus nidales, cerca de Cabanaconde y disfrutar de las variadas tradiciones costumbristas, cuyo calendario cubre casi todos los meses del año.

\section{Los grupos sociales}

Los distritos. Actualmente hay en el valle del Colca dieciséis poblaciones, distribuidas en distintas altitudes. Los centros poblados de la región puna, ubicados por encima de los 3,700 msnm son Tuti y Sibayo, en la margen derecha del río Colca; Callali, Canocota y Tisco en la margen izquierda. En la región intermedia de quechua y suni ${ }^{5}$, situados entre los 3,350 a 3,650 msnm, se ubican los pueblos de Coporaque, Ichupampa, Lari, Madrigal y Tapay, en el lado derecho; Chivay, Yanque, Achoma, Maca y Pinchollo, en el lado izquierdo. Cabanaconde es el centro poblado ubicado en zona de quechua baja, a una altitud de 3,287 msnm. Entre Tisco y Cabanaconde media una distancia de $100 \mathrm{~km}$, unido por una carretera afirmada que pasa por las poblaciones de la margen izquierda. Desde Chivay y de Yanque salen caminos carreteros que unen a los pueblos de la margen derecha del Colca y por un puente colgante situado en la parte baja de Cabanaconde se abre el camino de herradura hacia Tapay y los pequeños centros poblados que están situados al otro lado del río. Con

2 Pease, Franklin, Collaguas, Pontificia Universidad Católica del Perú, Lima, 1977.

3 Valderrama, M. y Escalante, C. Del Tata Mallku a la Mama Pacha, DESCO, Lima, 1988.

4 El Proyecto Majes consistió en la derivación de las aguas del río Colca represada en Condoroma mediante un túnel desde Tuti-Calera hasta los arenales de Sihuas, para irrigar más de 60,000 ha de tierras.

5 Clasificación de regiones, según Javier Pulgar Vidal (1996). 
excepción de Tapay, todas las poblaciones están unidas por carretera afirmada o carrosable, pero el Gobierno Regional de Arequipa tiene previsto la construcción de la carretera a este distrito apartado del valle. El centro más importante del Colca es Chivay, capital de la provincia de Caylloma y centro administrativo de la región. Fuera de la unidad geográfica del valle hay otras poblaciones igualmente importantes de esta provincia: Caylloma, ubicada en plena planicie de puna, a una altitud de 4,319 msnm; Huambo, población situada en otro microvalle al sur del Colca a una altitud de 3,322 msnm, Huanca a 3,080 msnm y Lluta a 3,000 msnm. El conjunto de las poblaciones mencionadas tienen distintas categorías, de acuerdo al ordenamiento político de la República. Chivay es distrito y capital de provincia. Otros distritos son: Achoma, Cabanaconde, Callali, Coporaque, Ichupampa, Lari, Madrigal, Maca, Sibayo, Tapay, Tisco, Tuti y Yanque. Situados fuera del contexto del valle, Caylloma, Huanca, Lluta, San Antonio de Chuca y Huambo también tienen la categoría de distritos. Algunas poblaciones como Acapi, Colca Peral, Llatica, Pinchollo, Canocota, son anexos de distrito o centros poblados menores.

Comunidades y sayas. Las mismas poblaciones del valle, sean distritos o anexos de distrito son, al mismo tiempo, comunidades campesinas ${ }^{6}$. Hay en el valle quince comunidades: Achoma, Cabanaconde y anexos (Pinchollo y Acapi), Canocota, Chivay, Coporaque, Ichupampa, Lari, Maca, Llacto Sayaña (en Sibayo), Colca Peral y Llatica (en Tapay), Ccota Ccota (en Tisco), Yanque Anansaya, Cassca y Yanque Urinsaya (en Yanque). Las comunidades de esta zona han sido reconocidas tardíamente. La primera en lograr su reconocimiento fue Ccota Ccota en el distrito de Tisco, el 28 de agosto de 1961 y la más reciente ha sido Lari, el 24 de mayo de 1991. Fuera del espacio propiamente del valle hay otras seis comunidades reconocidas, con la que se completan a diecinueve las comunidades campesinas reconocidas (Directorio, 1991). La razón de ser de las comunidades es el control comunal de tierras y de otros recursos como pastos, bosques y agua de riego. Cada comunidad, para los fines de su reconocimiento ha tenido que legitimar un espacio territorial de uso común, en cuyo interior se encuentran también las propiedades parcelarias de las familias (Figallo, 2007; Castillo et al., 2007). A su vez, cada comunidad campesina de este valle mantiene hasta hoy una antigua tradición de bipartición en parcialidades, denominado: anansaya (parcialidad de arriba) y urinsaya (parcialidad de abajo). El carácter dual de la organización social de las comunidades se expresa socialmente en diversas actividades de la vida comunal: subdivisión de espacios de cultivo, sistema de riego, obligaciones en cargos públicos, responsabilidades en las fiestas patronales, cultivos y cosechas comunales, etc. Achoma, Maca y Yanque están organizadas en sayas de anan y urin; Chivay agrega una tercera saya: Ccapa. Las otras comunidades han desactivado la bipartición formal.

Las poblaciones de hoy situadas en el valle mantienen las características básicas de las reducciones de indios, ordenada por la administración virreinal de Francisco de Toledo. Éstas consistieron en la concentración de varios ayllus en un solo centro poblado. Tanto en México como en Perú las poblaciones coloniales ordenadas por los conquistadores siguieron patrones europeos: una plaza, una iglesia, locales públicos alrededor de la plaza, calles en forma de cruz para formar manzanas en cuadrilátero donde se ubican los solares de las familias reducidas. Los centros poblados del valle del Colca tienen este patrón, como lo tienen en el resto del país donde se formaron las reducciones toledanas (Llosa y Benavides, 1994). En esta parte de Arequipa, las reducciones de indios fueron hechas en 1574. Se organizaron dieciséis reducciones y todas ellas continúan funcionando como centros poblados hasta hoy. En cada localidad del valle, el edificio más importante sigue

6 Las comunidades campesinas son organizaciones sociales del campesinado peruano que alcanzaron reconocimiento jurídico del Estado con la Constitución de 1920. 
siendo la iglesia, edificada durante los siglos XVI y XVII. Son construcciones barrocas, muy vistosas, con sus torres elevadas, hechas con piedra sillar. Sus naves son espaciosas; el altar y las paredes laterales de las iglesias están decorados con hornacinas y retablos dorados en pan de oro y pintados de colores, donde están las imágenes de la pasión y muerte de Cristo, así como de muchas imágenes del santoral cristiano. Sólo en la iglesia de Chivay hay 32 imágenes distribuidas en el interior y los aleros del altar mayor; en la iglesia de Yanque hay 26 imágenes; en la de Coporaque hay 21 imágenes, con Santiago como patrón del pueblo. En cada población hay una imagen principal, a la que llaman patrón o patrona del pueblo (Ráez, 2002). La fiesta al santo patrón o santa patrona es la más importante celebración anual en cada localidad. Las iglesias del Colca han merecido un estudio (Tord: 1983) y el Museo Regional de la Universidad Santa María de Arequipa, ubicada en Yanque, ha reproducido maquetas de todas las iglesias del valle. Actualmente, las iglesias coloniales de este valle están siendo reconstruidas, reparadas y redecoradas en sus características originales, con la intervención de la Agencia Española de Cooperación Internacional para el Desarrollo (AECID), que inició sus trabajos en 1998. La iglesia de Lari, probablemente la más hermosa por su estructura, decoraciones interiores, lienzos, campanarios y su elevada cúpula, ha sido totalmente reconstruida por la AECID, con participación de los mismos pobladores, especialmente capacitados para restaurar cuadros, retablos e imágenes esculturales; ese mismo trato ha recibido la iglesia de Maca, y actualmente vienen concluyendo con los retoques de las iglesias de Chivay, Coporaque y Yanque. Las casas familiares están hechas de piedra y adobe; están techadas de tejas o de calamina, pero hay casas que mantienen la antigua costumbre prehispánica: techo de paja.

Evolución demográfica. La población actual del valle alcanza a 23264 h (2007), sobre un total de $73718 \mathrm{~h}$ que tiene la provincia de Caylloma. De acuerdo a los datos de los cinco últimos censos nacionales (INEI), la evolución demográfica del valle en cerca de medio siglo es como aparece en el cuadro $\mathrm{N}^{\circ} 1$. La población censada de la zona, desde el censo de 1961 hasta el último del 2007, ha experimentado pocos cambios. Lo más significativo es que la población de Chivay, capital de la provincia, prácticamente se ha duplicado. En cambio, la mayoría de los distritos ha experimentado merma en su población, algunos de ellos muy significativos como en los casos de Cabanaconde, Maca, Madrigal, Tapay y Yanque. Muchas familias de estos distritos han trasladado sus residencias a Chivay, pero un buen sector de estas familias ha migrado a las ciudades de Arequipa y Lima. Razones laborales y el ideal de mejorar la educación de los hijos son los factores determinantes para la emigración hacia distintos destinos. Además de Chivay, han experimentado aumento de su población con respecto al censo de 1961, los distritos de Callali, Coporaque, Lari, Tisco y Tuti, pero en ningún caso es espectacular. Si observamos los totales censales, vemos que la población del valle se ha mantenido en general casi estacionario, con un lento crecimiento hasta el censo de 1981 y también en lento decrecimiento al 2007 . La migración del campo a la ciudad ha contribuido a este proceso. La ciudad de Arequipa ha crecido espectacularmente en cerca de 70 años, de 80947 h en 1940, a 158685 h en 1961 y a 821692 h en el 2007 (INEI). Por informaciones históricas tenemos referencias que la población del valle ha sido cambiante en sus distintas épocas. Cook (1977), utilizando varias fuentes estima que en 1530 había en el valle entre 62500 a 70000 h. De acuerdo al censo practicado en 1572, durante la administración del virrey Toledo, estudiado por Málaga (1973), alcanzaba a la cifra de 33900 h, mermado en casi el 50\% según las estimaciones de Cook, en poco más de cuarenta años de dominio español. Las informaciones de Vásquez de Espinoza, que datan de 1604, demuestran que la población del valle se había reducido aún más, a 24878 h. Esta tendencia de merma demográfica continuó durante todo el virreinato, 
tanto por las enfermedades endémicas como por la mortalidad de la población en las mitas mineras y otras formas de explotación ejercida sobre los vencidos como parte del etnocidio colonial (Wachtel, 1976; Valderrama y Escalante, 1988). Por este proceso de disminución de la población del valle, especialmente de varones, buena cantidad de tierras agrícolas e infraestructura de riego (canales y reservorios) fueron abandonados. Muchas terrazas abandonadas durante la etapa colonial y republicana no han sido restituidas, sino hasta las últimas décadas del siglo XX, con la valiosa acción de las ONG y programas especiales del sector público, restitución que aún no termina.

Cuadro N. ${ }^{\circ}$ 1. Población del valle del Colca según censos nacionales

\begin{tabular}{|r|l|r|r|r|r|r|}
\hline $\mathbf{N}^{\mathbf{0}}$ & Distritos & $\mathbf{1 9 6 1}$ & $\mathbf{1 9 7 2}$ & $\mathbf{1 9 8 1}$ & $\mathbf{1 9 9 3}$ & \multicolumn{1}{c|}{$\mathbf{2 0 0 7}$} \\
\hline 1 & Chivay & 3,322 & 3,460 & 3,833 & 4,032 & 6,532 \\
\hline 2 & Achoma & 1,432 & 1,476 & 1,646 & 1,442 & 1,139 \\
\hline 3 & Cabanaconde & 3,363 & 3,397 & 3,306 & 3,196 & 2,642 \\
\hline 4 & Callali & 1,843 & 1,788 & 2,766 & 3,152 & 2,511 \\
\hline 5 & Coporaque & 1,159 & 1,170 & 1,159 & 1,232 & 1,393 \\
\hline 6 & Ichupampa & 856 & 909 & 887 & 807 & 757 \\
\hline 7 & Lari & 1,069 & 1,239 & 1,156 & 1,255 & 1,373 \\
\hline 8 & Maca & 1,015 & 1,134 & 1,219 & 1,182 & 916 \\
\hline 9 & Madrigal & 1,040 & 2,055 & 3,698 & 1,122 & 705 \\
\hline 10 & Sibayo & 766 & 785 & 732 & 919 & 801 \\
\hline 11 & Tapay & 1,404 & 1,196 & 965 & 820 & 671 \\
\hline 12 & Tisco & 1,253 & 1,470 & 1,823 & 2,287 & 1,617 \\
\hline 13 & Tuti & 623 & 856 & 790 & 993 & 888 \\
\hline 14 & Yanque & 2,545 & 2,183 & 2,211 & 2,254 & 1,319 \\
\hline Total & & $\mathbf{2 1 , 6 9 0}$ & $\mathbf{2 3 , 1 2 0}$ & $\mathbf{2 6 , 1 9 1}$ & $\mathbf{2 4 , 6 9 3}$ & $\mathbf{2 3 , 2 6 4}$ \\
\hline
\end{tabular}

Fuente: Cuadro elaborado por el autor con los datos estadísticos del INEI.

\section{Collaguas y Cabanas}

Estudios de carácter documental, histórico, geográfico, arqueológico y antropológico realizados sobre el valle de Colca han confirmado que antes de la conquista de los incas, la región estuvo ocupada por dos grupos étnicos: los Collaguas procedentes del altiplano del Collao y los Cabanas de expansión Wari, Ayacucho (Neira, 1961; Wachtel, 1976; Pease, 1977; Cook, 1977; Manrique, 1985; Denevan, 1986 y 1988; Treacy, 1994). Por las declaraciones hechas por los mismos habitantes del valle en 1586, ante el Corregidor Ulloa, el origen mítico de estos dos grupos es explicado por historias míticas desde sus pacarinas principales; los collaguas declararon que descienden de la montaña Collaguata y los cabanas se declaran hijos del nevado Hualca Hualca; es decir, ambos grupos con una deidad y una cultura propia (Ulloa, 1885: 40). Sobre los grupos sociales que habitaron antes de los collaguas y cabanas tenemos pocas noticias. Sin embargo, las informaciones del mismo corregidor establecen que estos dos grupos étnicos se establecieron allí después de una victoriosa guerra: "Dicen que vencieron (a) los naturales y los echaron del pueblo é poblaron ellos" (Op. cit.: 40; Manrique, 1985: 31). Se puede colegir que la ocupación de este valle estuvo precedida de una confrontación bélica similar a la que ocurrió en la 
región Cajatambo, a lo que Pierre Duviols (1973) ha denominado “dualismo prehispánico de oposición y complementariedad" La diferencia estaría que en el valle de Colca, los nuevos ocupantes no se fusionaron con sus predecesores, los echaron de ese espacio y se establecieron apoderándose de todos los recursos existentes.

Los collaguas ocuparon la mayor extensión del territorio, tanto en espacios dedicados a la agricultura como de las amplias planicies de la puna de esta región, de abundantes pasturas naturales aptas para el pastoreo. Cuando Ulloa escribió esta información por orden de la corona española, las reducciones de indios ordenadas por Toledo ya estaban conformadas; prevalecían núcleos multiayllus. Por eso, el Corregidor, en su información menciona los nombres de las poblaciones reducidas, que son las mismas que existen hasta hoy. Da cuenta de la cantidad de tributarios en cada cabecera de provincia. Así, en Yanqui collagua "hay cuatro mil indios tributarios casados, sin los mozos é niños y viejos é mujeres...", dice el corregidor; luego agrega que en Lare Collagua "hay dos mil é quinientos tributarios", y en Cavana "hay mil é trescientos indios...", con los que suman 7,800 tributarios. Los centros administrativos principalesdel valle eran tres: Yanque Collagua, Lare Collagua y Cabanas, este último ocupaba la parte sur del valle, desde Pinchollo a Cabanaconde y microvalles situados hacia el oeste. Por su ubicación territorial, los cabanenses se convirtieron en excelentes agricultores de esta región ecológica, preferentemente especializados en el cultivo del maíz dulce (maíz sea). Cabanas y Collaguas vivieron probablemente con sus propias autonomías, manteniendo relaciones de intercambio entre ambos hasta la conquista de la región por los incas. Ulloa describe sobre la organización social de las reducciones del valle y sobre los rangos jerárquicos de los caciques del corregimiento, en las tres sedes provinciales, tanto en lo que corresponde a los caciques principales como a las segundas personas en el sistema de mando impuesto por los incas, que la colonia continuó manteniéndola para sus fines de dominación a los vencidos (Cook, 1977). La lengua de los collaguas era el aymara, probablemente por su origen colla y los cabanas hablaban el quechua, emparentado con la lengua de los cusqueños. Sus atuendos eran igualmente diferentes, con mayor cobertura los collaguas y menos indumentaria para los cabanas. Aunque el culto a los dioses generales eran los mismos, las ceremonias y rituales propiciatorios a la lluvia y a abundancia de los recursos producibles estaban fijados a sus dioses regionales particulares: a Collahuata el grupo de collaguas y a Hualca Hualca el de los cabanas. Estas diferencias culturales de collaguas y cabanas tienen todavía vigencia actualmente. Por influjo del dominio inca, el idioma quechua se impuso sobre el aymara, que está presente sólo en las toponimias y en algunos términos del habla quechua. En la indumentaria hay algunas diferencias actuales, especialmente en las de mujeres. En ambos sectores usan prendas bordadas, pero de las cabanenses son más profusos los bordados y más finas las telas. La diferencia más clara es en el sombrero femenino: las mujeres del lado collagua usan sombreros de palma, con cintas tipo blonda; las mujeres cabanenses usan sombreros de tela bordados con hilos de colores.

Cuando los quechuas cusqueños conquistaron la región durante el gobierno de Maita Cápac, aproximadamente en 1420, antes del período de expansión iniciada por el inca Pachacutec, como sugiere Nelson Manrique, el valle estaba ampliamente poblado por collaguas y cabanas, dedicados a la agricultura y al pastoreo, de acuerdo a los pisos ecológicos que controlaban. Fueron los incas quienes reordenaron la organización social de estos pueblos por el sistema decimal, reforzaron el control social y económico por el sistema dual de anansaya y urinsaya y establecieron una alianza política que contribuyó

7 Para el caso de Cajatambo, los dos grupos étnicos, waris y llacuaces, anteriores al dominio de los incas, se fusionaron culturalmente para formar una sociedad integrada entre pastores y agricultores. 
a afianzar la fidelidad de collaguas y cabanas hacia los gobernantes cusqueños, mediante el matrimonio del inca Maita Cápac con la hija del cacique de Yanque Collagua (Cook, 1977; Espinoza, 1987). Espinoza dice sobre esta alianza: "Maita Cápac tomó como esposa principal a Mama Tancaray, hija del Jatunmallco (rey) de Collagua (Cailloma)" (Espinoza, Op. cit. 1987: 56). Jatunmallco era el curaca principal de Yanque Collagua, con sede en Coporaque. Los actuales habitantes de esta localidad consideran que fue la belleza de la hija del Jatunmallco, llamada Mama Yacchi, la que conquistó al corazón del inca, quien la hizo su esposa principal. En demostración de su amor a Mama Yacchi o Mama Tancaray, "Maita Cápac mandó edificar un lujoso aposento para su bella esposa, cubierta de oro fino", dicen los informantes lugareños. Lo cierto es que el mencionado aposento estaba enchapado de cobre, corroborado por Fray Jerónimo de Oré, párroco de Coporaque, quien da cuenta que con ese metal hizo fundir cuatro campanas para la iglesia y el restante fue entregado a Gonzalo Pizarro, durante la guerra civil, para los herrajes de los caballos (Manrique, 1985: 48). En efecto, los restos del aposento, construido en piedras menudas y barro mezclado con paja, han resistido al tiempo: lo conservan hasta hoy como monumento. Junto a esta ruina prehispánica se ha edificado un alojamiento turístico, con el nombre de La casa de Mama Yacchi. Pero la fidelidad de los coporaquinos con el inca que desposó con una hija de ese pueblo y unió a los collaguas al Estado inca, tiene todavía su expresión contemporánea, cuando el municipio de Coporaque ha erigido un monumento de la efigie de Maita Cápac en el centro de su plaza.

\section{Agricultura bajo riego y pastoreo}

Desde tiempos prehispánicos, los habitantes del valle del Colca, han vivido de los frutos que proporciona la naturaleza, con la activa participación de la energía humana. El espacio que habitaron collaguas y cabanas está dividido en dos sectores ecológicos diferenciados por su uso: el espacio intermedio y bajo (1,200 a 3,700 msnm) dedicado a la agricultura y el espacio alto de puna (por encima de los 3,700 $\mathrm{msnm}$ ) dedicado al pastoreo de ganado. Para el laboreo agrícola, ha sido necesaria la asistencia del riego, mediante la construcción de una infraestructura especializada, que derive, almacene y haga llegar el agua hacia las sementeras mediante acueductos. En cambio, los grupos sociales que se especializaron en la cría de ganado no requirieron de infraestructura de alta tecnología, sino de la construcción de corrales y de un sistema racional de control de los espacios de pastoreo, en tiempo de lluvias y en tiempo de estío. Hasta donde tenemos información, la división dual de los espacios de vida especializados de los Andes ha tenido continuidad histórica: así lo encontraron los quechuas cusqueños cuando lo incorporaron a sus dominios, los colonizadores españoles también se beneficiaron de las dos formas de crear riqueza y la república ha heredado esta misma realidad. Al recorrer hoy el valle y la planicie alta del Colca encontramos que en lo fundamental esta estructura productiva es la misma de hace cinco siglos.

La agricultura. La parte agrícola del valle ha sido y sigue siendo un magnífico espacio para el cultivo de una gran variedad de productos de consumo. En los distintos períodos por los que ha pasado, la producción agrícola no sólo ha cubierto con creces el consumo necesario de sus propios habitantes, ha servido también para producir excedentes para el tributo incaico, colonial y republicano. Hoy produce también para el mercado. La tierra de esta región es pródiga y sus cultivadores son creativos para hacer producir a la tierra como ellos lo desean. Producen de todo lo que se cultiva en la región andina desde tiempos antiguos. Lo que cultivan, además de ser diverso, están debidamente adaptados 
a altitudes determinadas para su óptimo desarrollo, que los campesinos conocen por milenaria experiencia. El geógrafo alemán Carl Troll (1945) hizo un análisis del sistema de producción agrícola andina basado en escalones ecológicos. Cuatro décadas más tarde, Murra (1975), Fonseca (1983), Mayer (2004) y otros confirmarían y ampliarían las ideas de Troll para el caso de Huánuco, Yauyos y Cusco. En primer lugar, para Troll: "La agricultura es la raíz de toda cultura y donde ella se desarrolla y afina, florece también la cultura espiritual y social". Haciendo referencia a los escalones climáticos equivalentes a los del valle de Colca asevera con precisión, que

"La base para el desarrollo de la agricultura en los escalones de clima frío de los Andes eran plantas cultivables, específicamente andinas y en primerísima línea las plantas de tubérculos (papa, oca, massua y olluco) que hicieron también posible la ocupación permanente y el hábito sedentario de los indios por encima del escalón de cultivo de maíz y además el de Atriplex (chenopodium) de los Andes, la quinua y la cañihua, las únicas plantas con semillas en forma de granos por encima del límite del maíz.” (Troll, 1945: 17.18).

Esos mismos productos siguen cultivándose en el valle, de acuerdo a sus altitudes. El maíz (Zea mays), diferenciado en esta región como maíz dulce ${ }^{8}$ se ha cultivado desde antiguo y se sigue cultivando entre los 2800 a más de $3300 \mathrm{msnm}$. Las tierras de Cabanaconde son las más aptas para este producto y hasta la fecha los cabanenses siguen siendo excelentes cultivadores para abastecer al valle y al mercado regional. Asimismo, las tierras bajas y riberas del río, de Tapay, Madrigal, Lari, Ichupampa y Coporaque por la margen derecha y de Pinchollo, Maca, Achoma y Yanque por la margen izquierda también han cultivado y cultivan el maíz dulce. Por el calentamiento del planeta y los consecuentes cambios climáticos, hoy se cultiva maíz dulce hasta los $3600 \mathrm{msnm}$. La papa (Solanum de varias especies), en cambio, se cultiva en distintas altitudes, desde zonas semicalientes hasta las frías. El mejor clima para las variedades de papa está entre los 2500 a $3700 \mathrm{msnm}$. Por encima de esta altitud se cultiva la papa blanca conocida como shiri o papa amarga de clima frío. También continúan cultivando oca (Oxalis tuberosa), mashua (Tropaeolum tuberosum) y olluco (Ullucus tuberosus), preferentemente para el consumo doméstico. Estos productos se desarrollan mejor en climas semifrígidos, entre los 3,300 a 3,800 msnm. En cambio la quinua (Chenopodium quinoa), la cañigua (Chenopodium pallidicaule) y la quiwicha (Amaranthus caudatus) se siguen cultivando en climas intermedios, tanto para el consumo doméstico como para el exigente mercado urbano. Otros cultivos venidos de Europa, como la haba (Vicia faba I.), el trigo (Triticum spp), la cebada (Hordeum bulgare), la avena (Avena sativa) se han adaptado a climas diversos. Las habas alternan las tierras del maíz en Cabanaconde como con las tierras de ocas y ollucos de Tuti, Callali y Sibayo; son muy versátiles como la cebada y la avena. No es lo mismo con el trigo, que es un producto más delicado y de buena asistencia de riego. El trigo se desarrolla óptimamente entre los 3,000 a 3,600 msnm en sus diversas variedades.

Según los datos de la Agencia Agraria de Caylloma, hay en el valle, un total de 10 024.80 Ha. de tierras cultivadas, incluyendo al distrito de Huambo, situado en otro micro valle contiguo al Colca. De esta cantidad, $9639.24 \mathrm{Ha}(96,16 \%)$ se cultivan bajo riego; las restantes 385.56 Has (3.84\%) se cultivan en secano9. A pesar de que la agricultura de la región ha experimentado cambios en pro de la modernización, el sistema de riego sigue siendo por

8 Los campesinos denominan maíz dulce a la variedad de maíz que sirve para la cancha, es decir, el maíz tostado de pulpa blanda, para diferenciarlo del maíz amarillo o duro que se cultiva en las cabeceras de costa y costa, por debajo de los 2,000 msnm, a la que llaman también "maíz de gallina".

9 Son los cultivos que no se riegan, se cultivan con las bondades de la temporada de lluvias de cada año. 
gravedad, como lo han practicado tradicionalmente. Según los técnicos del Ministerio de Agricultura, los campesinos son resistentes a adoptar nuevas formas de riego, por goteo o por aspersión, que por el momento han sido sólo demostrativos y experimentales. En cambio, en los proyectos de irrigación de Sihuas y Majes del valle costero de esta misma cuenca, los colonos han aprendido a irrigar sus tierras por el sistema moderno.

Por regla general, en todas las poblaciones, comunidades, anexos y sectores agrícolas, el riego se maneja mediante las 31 Comisiones de regantes (Cuadro $\mathrm{N}^{0} 2$ ). Existen en el valle un total 6,307 usuarios que conducen 32,903 parcelas de distintos tamaños y situados en distintas pisos ecológicos. Esto es así porque en todo este ámbito se registra un determinado número de usuarios o unidades domésticas, que controlan varios predios o parcelas de cultivo por unidad familiar. En algunas localidades hay pocos usuarios, como en Llatica que tiene sólo 34 regantes, pero hay allí 198 parcelas, es decir casi 6 parcelas por usuario. En cambio, en Yanque Anansaya se concentran 488 usuarios para 1,851 parcelas, que dan un promedio de 3.8 parcelas por usuario. En cualquiera de los casos se trata de minifundios, que en su mayoría está por debajo de una hectárea por parcela; es decir, es una región donde el minifundio es la característica dominante. Por otro lado, hay en el valle propiedades en terrenos planos, pero la mayor cantidad de parcelas están ubicadas en laderas, por lo que ha sido necesaria la andenería. En la mayoría de las poblaciones son pocas las familias que controlan el mayor número de predios y de las mejores tierras, que contrasta con la mayoría de los campesinos que tiene pocas parcelas, de pequeña extensión y en lugares menos accesibles. La otra característica es que cada familia procura asegurarse de por lo menos una parcela en diferentes pisos ecológicos, que le permita disponer de tierras para distintos tipos de cultivos, preferentemente tierras de maíz, de tubérculos y de cereales. En cambio los cultivos en secano son pocas, tiende a desaparecer con la tecnificación del riego y el aumento de capacidad de riego que el proyecto Majes ha proporcionado a algunas comunidades.

Los principales cultivos que ocupan la mayor cantidad de tierras de cultivo en el valle son diez. La extensión de productos que se cultivan en hectáreas es como sigue: alfalfa 1702 , papa 1558 , haba verde 1451 , maíz amiláceo 1441 , arveja grano verde 445 , cebada grano 336, tuna 271, haba seca 150 , maíz choclo 130 , avena forraje 114 . La extensión total que ocupan estos cultivos en la campaña del 2007 alcanzó las 8325 hectáreas, es decir, el $83,5 \%$ del total de tierras cultivables. De esta cantidad, los productos forrajeros (alfalfa y avena) utilizan 1816 hectáreas; la alfalfa que se cultiva en todos los pueblos y la avena sólo en las localidades de altura como Tuti y Sibayo. La papa se cultiva igualmente en todos los pueblos, mientras que el maíz sólo en las comunidades por debajo de los $3600 \mathrm{msnm}$. La importancia de la alfalfa y de la avena estriba en la generalizada crianza de animales domésticos que requieren de este recurso, que se complementa con la crianza doméstica de animales menores, especialmente del cuy (cavia porcellus). En la actualidad, los campesinos del valle del Colca supeditan sus cultivos en función de los vaivenes del mercado urbano, pero los productos que siembran son casi los mismos de antaño, con la adición de productos agrícolas venidos de Europa. Por necesidad interna para la complementación alimentaria, por los cambios modernos en la dieta y la exigencia del mercado, se cultivan también otros productos no tradicionales: cebolla, zanahoria, perejil y otros. Algunos cultivos experimentales, como lo ocurrido con la alcachofa, han sido sólo eso, experimentos. No resistió a las heladas, que en esta región son fuertes y frecuentes tampoco a los bajos precios en el mercado. 
Cuadro $\mathrm{N}^{\circ}$ 2. Terrenos de cultivo bajo riego

\begin{tabular}{|c|c|c|c|c|}
\hline $\mathbf{N}^{\mathbf{0}}$ & Comisiones de regantes & Área bajo riego (ha) & $\mathbf{N}^{0}$ de usuarios & $\mathbf{N}^{0}$ de predios \\
\hline 1 & Achoma Anansaya & 622,00 & 282 & 1573 \\
\hline 2 & Achoma Urinsaya & 617,00 & 318 & 1560 \\
\hline 3 & Canocota & 185,00 & 117 & 998 \\
\hline 4 & Chivay Anansaya & 240,00 & 319 & 813 \\
\hline 5 & Chivay Ccapa & 106,00 & 121 & 322 \\
\hline 6 & Chivay Urinsaya & 200,00 & 471 & 916 \\
\hline 7 & Coporaque & 443,00 & 323 & 2280 \\
\hline 8 & Cosñirhua Malata & 85,75 & 88 & 424 \\
\hline 9 & Tapay & 80,00 & 130 & 395 \\
\hline 10 & San Juan de Chuccho & 50,00 & 66 & 247 \\
\hline 11 & Huambo Campiña & 690,00 & 250 & 1745 \\
\hline 12 & Huambo Chinini & 200,00 & 170 & 506 \\
\hline 13 & Huambo Zona Regulada & 126,97 & 116 & 223 \\
\hline 14 & Ichupampa & 441,81 & 265 & 1667 \\
\hline 15 & Lari & 530,00 & 300 & 1340 \\
\hline 16 & Llanca & 60,00 & 100 & 296 \\
\hline 17 & Llatica & 40,00 & 34 & 198 \\
\hline 18 & Maca Anansaya & 559,26 & 342 & 1673 \\
\hline 19 & Maca Urinsaya & 308,00 & 160 & 1525 \\
\hline 20 & Madrigal & 370,00 & 261 & 2828 \\
\hline 21 & Sibayo Cuenca Alta & 20,00 & 94 & 99 \\
\hline 22 & Tuti & 360,00 & 298 & 1478 \\
\hline 23 & Yanque Anansaya & 709,66 & 488 & 1851 \\
\hline 24 & Yanque Urinsaya & 239,79 & 208 & 923 \\
\hline 25 & Pinchollo & 590,00 & 170 & 2180 \\
\hline 26 & Cabanaconde Campiña & 720,00 & 355 & 4187 \\
\hline 27 & Castropampa & 381,00 & 99 & 270 \\
\hline 28 & Las Joyas & 180,00 & 119 & 119 \\
\hline 29 & Media Luna & 174,00 & 87 & 87 \\
\hline 30 & Villa El Colca & 150,00 & 76 & 76 \\
\hline 31 & Acpi & 160,00 & 80 & 104 \\
\hline \multicolumn{2}{|c|}{ Totales } & $9.639,24$ & 6307 & 32903 \\
\hline
\end{tabular}

Fuente: Agencia Agraria de Chivay, 2008.

La tecnología que usan hoy para roturar la tierra de cultivo en las chacras linda entre lo tradicional y lo moderno. Esencialmente depende de la naturaleza del terreno en la que trabajan. En las plataformas angostas, la siembra se hace con la chaquitaklla, la herramienta prehispánica más versátil que sigue usando el campesino de esta región 
(Morlon, 1996; Bourliaud et al., 1988), ya sea en forma individual o colectiva; para los aporques del maíz y la papa usan la azada con reja de metal y también la lampa. También usan herramientas de fabricación industrial, como la barreta, el pico y la lampa, que se emplean para distintos usos y para variados tipos de terreno. En los terraplenes suficientemente anchos y en partes planas y semiplanas trabaja mejor la yunta de bueyes, técnica generalizada en todo el valle. Otro tipo de animales de tiro son los equinos: caballos y burros, que también intervienen para los trabajos de barbecho y de siembra. Desde hace algunos años, ha entrado al valle el uso del tractor para roturar la tierra en terrenos planos. Este recurso motorizado, que funciona a petróleo, trabaja especialmente en la agricultura dedicada al mercado, aun cuando su costo es alto y excluye parcialmente la participación tradicional de la mano de obra campesina. Por estas innovaciones, la chaquitaklla y el tractor, son las dos antípodas tecnológicas que aparecen hoy en el escenario agrícola del valle del Colca.

Volumen de producción. Utilizando todos los recursos y tecnología disponible, los resultados de la producción agrícola es significativa. Se autoabastece al consumo regional y producen para el mercado, preferentemente para la creciente ciudad de Arequipa. La alfalfa es el producto más rentable y necesario en el valle (18 $000 \mathrm{~kg} / \mathrm{ha})$, pero su comercialización es fundamentalmente local y la capital de la provincia. Otros productos agrícolas comercializables se cultivan en menor extensión. El rendimiento por hectárea ${ }^{10}$ de estos productos, según datos oficiales, son como sigue: papa (Yungay, canchán, cica) $13500 \mathrm{~kg} / \mathrm{ha}$; habas verde $1980 \mathrm{~kg} / \mathrm{ha}$; habas seco $1500 \mathrm{~kg} / \mathrm{ha}$; maíz $990 \mathrm{~kg} / \mathrm{ha}$; arveja $1500 \mathrm{~kg} / \mathrm{ha}$; trigo $1200 \mathrm{~kg} / \mathrm{ha}$; cebada $1200 \mathrm{~kg} / \mathrm{ha}$; orégano $18000 \mathrm{~kg} / \mathrm{ha}$, este último da tres cosechas al año, de $6000 \mathrm{~kg} / \mathrm{ha}$ por cada corte, igual que la alfalfa. Los precios de cada producto en el mercado de Chivay y de Arequipa varían constantemente, de acuerdo a la demanda, la competencia y de la política mercantil de los intermediarios que compran las cosechas en las mismas localidades. Los costos de producción de los recursos agrícolas aumentan a medida que se encarecen los insumos. En algunas campañas agrícolas, los costos altos de abonos e insecticidas, sumados a los costos del alquiler de yuntas de bueyes o de tractores para los terrenos planos y semiplanos, supera a los precios de la comercialización. Por esta razón, el campesino medio y con escasas tierras de cultivo prefiere sembrar sólo lo que necesita para el consumo familiar. Estas dificultades afectan también a los crianderos de ganado ovino y de camélidos sudamericanos de los pueblos del alto Colca. Tanto a los agricultores como a los ganaderos les afectan los vaivenes de precios. Hasta la fecha no han logrado enfrentar organizadamente la comercialización de la producción campesina.

La ganadería. Otra actividad económica de igual importancia es la crianza de ganado, que en términos generales se denomina ganadería. Esta actividad involucra a la mayoría de las familias del valle, por lo que resulta necesario distinguir formas de crianza y tipos de ganado que se crían. En primer lugar, son dos las modalidades sociales de crianza de ganado: la crianza exclusiva de ganado y la crianza de ganado asociada a la agricultura. La primera es una actividad especializada de crianza que se practica tradicionalmente en las poblaciones altas, que consiste en pastar ganado en las mesetas de puna, por encima de los $3700 \mathrm{msnm}$. La segunda modalidad se practica en las poblaciones propiamente del valle, entre las familias campesinas que viven en pueblos situados entre los 1200 a $3700 \mathrm{msnm}$. Especializados en el manejo del ganado desde tiempos prehispánicos, los pastores de puna, crían preferentemente camélidos sudamericanos: llamas (Lama glama) y alpacas (Lama glama pacos), de los que se benefician en carne, lana, cueros

10 La otra medida de producción es por topos, que viene a ser la tercera parte de la producción por hectárea. 
y la llama les sirve también como animal de carga. Desde la introducción de ganado europeo, se han adaptado a estos espacios la crianza de ovinos (Ovis aries) de distintas razas y equinos (Equus caballus), que les sirve como animal de transporte. Aun cuando el pastoreo altoandino ha pasado por distintas etapas históricas ${ }^{11}$, en la actualidad, la crianza de animales en las mesetas altas es de tipo familiar. Cada unidad doméstica pasta su ganado en espacios comunales, debidamente regulados por la organización comunal, mediante un sistema de rotación. La otra forma de crianza, la que alterna con la actividad agrícola, es mucho más variada. Las familias agricultoras de las poblaciones del valle crían preferentemente ganado vacuno (Bos taurus), por los amplios beneficios que les reporta, por constituir un fondo de reserva para las familias campesinas como por el aprovechamiento de la leche y de sus derivados para el consumo familiar y la comercialización. También crían ovinos (Ovis aries), equinos (Equus caballus), porcinos (Sus scrofa doméstica) y caprinos (Capra) y evidentemente el asnal (Equus asinus), que sigue siendo el principal animal de carga para acopiar las cosechas. El ganado que crían los agricultores requiere de forrajes cultivados, especialmente de la alfalfa (Medicago sativa), avena (Avena sativa) y cebada forrajera (Hordeum vulgare), así como el uso del trébol (Trifolium) y los pastos de rastrojos de las sementeras después de las cosechas. Tanto en los pueblos de economía agrícola como en los pueblos de pastores altoandinos se crían también animales menores, gallinas (Gallus gallus) y patos (Cairina moschata), y el infaltable cuy (Cavia porcellus) andino ${ }^{12}$.

Hay una considerable población ganadera en el valle del Colca, registrado por la Agencia Agraria de Caylloma y DESCO, tanto en variedad como en cantidad, que lo vemos en los cuadros $\mathrm{N}^{\mathrm{o}} 3$ y $\mathrm{N}^{\mathrm{o}} 4$. El primer cuadro nos muestra la población ganadera nativa, que se cría en todas las poblaciones, en distintas cantidades. Evidentemente, son los pueblos de las mesetas de puna las que encabezan en el volumen de población. Callali es la comunidad que concentra la mayor cantidad de camélidos sudamericanos, con 58320 alpacas y 25379 llamas, que hacen un total de 83699 animales. Le sigue Caylloma, con 52926 alpacas y 22892 llamas, que hacen un total de 75,818: la tercera es Tisco, con 55902 alpacas y 15 895 llamas, que totalizan a 71797 animales. Huambo viene a ser la población con menor cantidad de ganado nativo, con un total de 890. Esto se explica por estar fuera de las amplias mesetas especializadas en esta ganadería y por la menor amplitud de sus tierras de altura, aptas para el pastoreo.

¿Cómo es que todos los pueblos del valle, aún estando fuera del territorio de puna crían camélidos sudamericanos? La respuesta a esta pregunta es que los territorios de todas estas poblaciones se prolongan hasta la puna, por un sistema de control de espacios que viene desde tiempos prehispánicos. El control vertical de archimpiélagos como ideal del hombre andino, que John Murra (1972) propuso a partir de los documentos coloniales de Huánuco y Chucuito, funciona en el valle del Colca. Por el lado de la población ganadera de animales que vinieron de Europa y que se han andinizado muy bien (Cuadro No 4), presenta otros rasgos en los pueblos del valle. En primer lugar, vacunos y caprinos son animales mejor adaptados en zonas ecológicas intermedias, hasta una altitud de 3700 msnm. Sin embargo, los vacunos criollos están adaptados a distintas altitudes, desde zonas

11 Un estudio puntual sobre la comercialización de la lana en tiempos del dominio del sistema de haciendas, es el libro Lana y capital mercantil en el sur: la casa Riketts, 1895-1935, de M. Burga y W. Reátegui (1981).

12 El animal doméstico más preciado para las familias del valle del Colca y de toda la zona andina es el cuy, de alto valor nutricional, que se reproduce rápidamente y pueden consumirlo en cualquier ocasión, especialmente en actos ceremoniales. El cuy convive con las familias, preferentemente en las cocinas o en corrales especiales; por el papel innovador de las ONG y agencias de gobierno se vienen implementando también formas de crianza comercial del cuy, que incluye el mejoramiento genético. 
calientes hasta la puna. Es eso lo que se ve en el cuadro, población vacuna en todas las localidades, incluyendo en comunidades de la zona altiplánica. En cambio los caprinos pueden pastar sólo en climas semi calientes o calientes de cabeceras de valle y en la costa marítima. Los ovinos son animales que se han adaptado perfectamente en climas fríos de las altiplanicies andinas y comparten pasturas con los camélidos sudamericanos. Por esa razón hay mayor cantidad de ganado ovino en Callali (45 389), Tisco (42 739), Caylloma (41 130), esta última localidad situada fuera del ámbito del valle, en plena altiplanicie, a una altitud de 4319 msnm.

Por los datos del Censo Agropecuario de 1993 y del monitoreo permanente de los técnicos del Ministerio de Agricultura, se estima que en el valle hay una considerable población pecuaria, con 308742 alpacas, 125982 llamas, 42154 vacunos, 224518 ovinos y 3842 caprinos, 3700 porcinos, para una población estimada de 7,500 familias, sobre un total de 23264 habitantes, dedicados a la agricultura y la crianza de ganado. Si sumamos la producción agrícola con la producción ganadera en las poblaciones del valle del Colca, comprobamos que se crea suficiente riqueza para abastecer los requerimientos básicos para la alimentación regional. No queremos decir con esto que los pueblos de este valle son autosuficientes para una vida óptima, lo que está a la vista es que no sufren hambre, mientras no aparezcan calamidades que afecten la producción. La pobreza es un fenómeno social que existe en todas partes del país, pero en el valle del Colca la pobreza es relativa. Lo importante es que casi todos tienen sus viviendas, sus tierras de cultivo, sus animales de cría; las localidades tienen fluido eléctrico, carreteras de enlace, servicio de transporte y alimentos producidos por ellos mismos.

Cuadro $\mathbf{N}^{\circ}$ 3. Camélidos sudamericanos en el valle

\begin{tabular}{|l|l|r|r|r|}
\hline \multicolumn{1}{|c|}{$\mathbf{N}^{\mathbf{0}}$} & \multicolumn{1}{|c|}{ Centros poblado } & Alpacas & Llamas & Totales \\
\hline 1 & Achoma & 3107 & 455 & 3562 \\
\hline 2 & Cabanaconde & 2106 & 892 & 2998 \\
\hline 3 & Callali & 58320 & 25379 & 83699 \\
\hline 5 & Chivay & 14090 & 1895 & 15985 \\
\hline 6 & Caylloma & 52926 & 22892 & 75818 \\
\hline 7 & Coporaque & 10416 & 1597 & 12013 \\
\hline 8 & Huambo & 696 & 194 & 890 \\
\hline 9 & Ichupampa & 2842 & 985 & 3827 \\
\hline 10 & Lari & 12120 & 6895 & 19015 \\
\hline 11 & Maca & 1038 & 189 & 1227 \\
\hline 12 & Madrigal & 1656 & 558 & 2214 \\
\hline 13 & San Antonio de Chuca & 31228 & 18597 & 49825 \\
\hline 14 & Sibayo & 14142 & 8945 & 23087 \\
\hline 15 & Tapay & 12145 & 2359 & 14504 \\
\hline 16 & Tisco & 55902 & 15895 & 71797 \\
\hline 17 & Tuti & 12576 & 5359 & 17935 \\
\hline Totales & Yanque & 23432 & 12896 & 36328 \\
\hline
\end{tabular}

Fuente: Agencia Agraria de Caylloma: 2008. 
Cuadro $\mathbf{N}^{\circ}$ 4. Población pecuaria en el valle del Colca

\begin{tabular}{|l|l|r|r|r|r|}
\hline $\mathbf{N}^{\mathbf{0}}$ & Centros poblados & Vacunos & \multicolumn{1}{c|}{ Ovinos } & \multicolumn{1}{c|}{ Caprinos } & \multicolumn{1}{c|}{ Totales } \\
\hline 1 & Achoma & 2940 & 3687 & 195 & 6822 \\
\hline 2 & Cabanaconde & 3150 & 2674 & 415 & 6239 \\
\hline 3 & Callali & 3450 & 45389 & 315 & 49154 \\
\hline 4 & Chivay & 2350 & 10755 & 855 & 13960 \\
\hline 5 & Caylloma & 2380 & 41130 & 0 & 43510 \\
\hline 6 & Coporaque & 3880 & 3730 & 191 & 5901 \\
\hline 7 & Huambo & 1950 & 2856 & 349 & 7771 \\
\hline 8 & Ichupampa & 2480 & 5155 & 210 & 5155 \\
\hline 9 & Lari & 1940 & 1238 & 129 & 7845 \\
\hline 10 & Maca & 1890 & 1385 & 120 & 3307 \\
\hline 11 & Madrigal & 855 & 16209 & 0 & 17064 \\
\hline 12 & San Antonio de Chuca & 2487 & 18145 & 126 & 20758 \\
\hline 13 & Sibayo & 859 & 1539 & 85 & 2483 \\
\hline 14 & Tapay & 2958 & 42739 & 86 & 45783 \\
\hline 15 & Tisco & 3150 & 7377 & 149 & 10676 \\
\hline 16 & Tuti & $\mathbf{4 2 1 5 4}$ & $\mathbf{2 2 4 5 1 8}$ & $\mathbf{3 8 4 2}$ & $\mathbf{2 7 0 5 1 4}$ \\
\hline 17 & Yanque & & & 20691 \\
\hline Totales & & & & \\
\hline
\end{tabular}

Fuente: Agencia Agraria de Caylloma: 2008.

\section{Conservación de los espacios artificiales}

Uno de los distintivos de identidad del valle del Colca son sus andenes ${ }^{13}$. Son plataformas artificialmente construidas para ganar tierras de cultivo, mediante la construcción de muros de piedra menuda en todos los terrenos declives, a lo largo del valle, desde Coporaque hasta Cabanaconde. De acuerdo a la naturaleza del terreno, hay andenes de forma rectilínea, semicircular, circular, serpenteante, que se superponen unas tras otras, convirtiendo terrenos inclinados en largas mesetas cultivables. Los espacios ganados para la agricultura son de distintas longitudes y su anchura depende del grado de inclinación del terreno; por lo que hay andenes de hasta 30 y $40 \mathrm{~m}$ en terrenos semiplanos, como también hay andenes sumamente angostos de apenas 5 a $6 \mathrm{~m}$ de ancho en terrenos de inclinación pronunciada. El ingenio tecnológico ha logrado en el Colca, la construcción de andenes de suficiente inclinación del terreno para utilizar el riego por gravedad y de suficiente tierra para hacer de seis a más surcos o camellones. Por la parte del fondo de los andenes pasa el canal de riego, para que mediante el trabajo de filigrana de los regadores, especializados en el manejo del agua en espacios muy angostos, extiendan el agua por tiempo controlado, sin que los muros puedan desplomarse por exceso de humedad. En las andenerías largas, los ingenieros andinos han dispuesto una suerte de escalera (Takilpus), de evidente influencia cusqueña, para subir y bajar de una plataforma a otra, mediante la colocación de piedras largas que se usan como escalones. Toda esta extraordinaria ingeniería agrícola, le da al

13 En el lenguaje popular se denominan andenes a los muros artificiales hechos para ganar tierras cultivables en planos inclinados. Técnicamente se denominan terraplenes, terrazas o plataformas. 
valle un paisaje cultural impresionante hacia ambos lados del río. La naturaleza agreste, accidentada y en constante erosión por las fuerzas de la naturaleza y la acción del hombre, ha sido dominada por la creatividad de los grupos humanos que la han habitado desde antiguo.

¿Qué antigüedad tienen estos andenes en el valle del Colca? Los estudios arqueológicos coinciden en afirmar que son obras de ingeniería hidráulica prehispánica, pero no han determinado con precisión a qué época corresponden en distintos pueblos. Son varios los trabajos arqueológicos emprendidos para determinar su antigüedad, tanto de nacionales como de extranjeros. El trabajo pionero es de Máximo Neira, cuya tesis doctoral data de 1961. Los trabajos mejor sistematizados han sido hechos en los años ochenta y noventa (Neira, 1986; Vera Cruz, 1987; Denevan, 1986 y 1988; Treacy, 1994). Los trabajos del fechado radiocarbónico de las terrazas en el valle, basados en el análisis de la cerámica encontrada en sus estratos, especialmente en Coporaque y Cabanaconde, establecen varios períodos de construcción. Los más antiguos pertenecerían al período intermedio tardío y los más recientes al período inca. Fechados realizados por Vera Cruz y Neira, citado por Treacy, establecen que los materiales cerámicos más antiguos encontrados en Cabanaconde corresponden a "una variante de la alfarería Wari". Teniendo en cuenta que la expansión Wari, desde su centro administrativo situado en Ayacucho, se inició alrededor del 600 a.C., las afinidades de las cerámicas de Cabanaconde con las de Wari serían claros indicios de que las construcciones más antiguas de terrazas agrícolas del valle están asociadas a ese periodo de expansión. En un cuadro de selección de fechados de radiocarbono presentado por Treacy (1994: 100) aparece la secuencia de fechados en las terrazas de Coporaque, que van desde el 300 hasta 1370 d.C., es decir desde antes de la expansión Wari hasta los comienzos del periodo inca calculado por algunos historiadores.

No contamos con datos sobre la ocupación anterior de Collaguas y Cabanas, quienes habrían sido los primeros en implementar el sistema de andenes en esta región. En cambio hay abundantes datos sobre la conquista inca de este territorio y su papel en el reordenamiento social y del perfeccionamiento de la agricultura bajo riego. Fueron los incas los que se esforzaron por mantenerlo, mejorarlo y ampliarlo, con las técnicas más avanzadas de la ingeniería hidráulica que traían de sus experiencias en los valles cusqueños. Fueron los incas, los que ampliaron la frontera agrícola en el valle, mediante la ampliación longitudinal de los canales, la construcción de nuevos acueductos y reservorios en las nacientes de los manantiales y la sistematización del riego por inundación, con el uso racional de los surcos sobre los terraplenes. A los incas también se les atribuye el enriquecimiento de la agricultura, con un sistema de selección de semillas y con una mayor variedad de cultivos. Especialmente con la papa y el maíz, los incas contribuyeron con llevar nuevas variedades de papa, tanto en colores, formas y arenosidad, adaptadas a distintas altitudes. Igualmente, perfeccionaron la organización social del trabajo colectivo, implantando el sistema decimal en el empleo de mano de obra, en la chacra, en la construcción y reparación de canales y reservorios, en el mantenimiento de las sementeras y en el acarreo de las cosechas. Sobre la experiencia de collaguas y cabanas se agregó la sabiduría tecnológica de los incas, con quienes se concluyó en la construcción de los andenes hasta donde el terreno del valle lo permitió. Por esta secuencia de ocupaciones, se puede concluir -en base a la opinión de los estudios arqueológicos-, que la estructura de los andenes del valle del Colca responde a tres períodos temporales: la fase anterior a los collaguas y cabanas, es decir, anterior al 600 d.C.; la fase de ocupación propiamente de cabanas y collaguas, entre los años 600 a 1300 d.C. aproximadamente, y la fase de la conquista de los quechuas. Hay por eso, en los cálculos de la antigüedad de los andenes, una secuencia escalonada de más de mil años, antes de la invasión española. 
En los Andes peruanos, como en todas partes del mundo, la agricultura es una actividad que ha evolucionado a partir de experiencias naturales de reproducción de plantas comestibles. La humedad dejada por los ríos de los grandes valles y las temporadas anuales de lluvias que hacen germinar, crecer y madurar las semillas y la experiencia vital del hombre, han sido en todas partes los factores originarios de la agricultura. En torno a este proceso, los arqueólogos coinciden en la tesis de que los terraplenes del valle del Colca fueron construidos primero para cultivar en secano. El sistema de irrigación habría sido un proceso gradual y posterior a las terrazas más antiguas. La construcción de chacras en terraplenes para ganar tierras útiles para el cultivo y la naturaleza inclinada del terreno muestran "...que los agricultores transformaron las chacras de secano en chacras con riego" (Treacy, Op. cit.: 102), con la que intensificaron la producción agrícola en este valle. Lo que es evidente en la agricultura andina es que el cultivo en secano en terrenos naturales ha sido una tradición temprana; por esa razón, resulta coherente el supuesto de que los andenes más antiguos del valle del Colca sirvieron para el cultivo en secano. Si esto ocurrió en Colca, tiene que haber ocurrido también en otros lugares de los Andes. En cambio, nadie duda que la agricultura andina se desarrolló a partir de la experiencia de cultivos de terrenos de secano. A pesar de su antigüedad, la tradición de cultivar productos vegetales con la humedad que provoca la lluvia estacional no ha sido olvidada por el campesinado andino, lo continúan practicando en muchos lugares de la sierra peruana. Para los mismos campesinos del Colca, los productos cosechados en terrenos sin riego son mucho más variados y los más apreciados por su calidad. Varios tipos genéticos de papas, ocas, ollucos y mashuas, son productos que se cultivan preferentemente en tierras de secano. "No se desarrollan bien en tamaño, pero son más arenosas y agradables", dicen los informantes. En este valle arequipeño, los cultivos en secano tienden a disminuir, pero todavía lo practican. Los datos estadísticos estiman en $386 \mathrm{Ha}$., que representan el 4.0\% del total de tierras cultivables, como ya se indicó. El riego con las aguas reguladas del canal Tuti-Majes ha contribuido a mermar los cultivos en secano.

\section{Escasez de agua y ritos agrarios}

La orografía del valle del Colca es profundamente irregular, como en todos los valles que se proyectan desde los Andes al Océano Pacífico. Hacia ambos lados del valle están las altas montañas con sus múltiples pliegues naturales y por el centro corre el río Colca, por una profunda depresión corroída por el agua en millones de años. Por esta razón, Juan de Ulloa decía en su informe al rey de España en 1586: "Del río principal no se aprovechan de sacar acequias ni de beber dél ni de otra cosa alguna, porque va muy bajo y canalado..." (Ulloa, Op. Cit.: 1885: 41). Así es en efecto, la profundidad por la que discurre el río no ha permitido que los distintos grupos sociales que la han habitado puedan aprovechar de esas aguas para el riego. Sólo con la llegada del moderno proyecto de irrigación de Majes ha sido posible derivar esas aguas por un túnel hacia la costa. De esa derivación, sí aprovechan las comunidades situadas en el lado izquierdo del río, pero no los del lado derecho. La imposibilidad de utilizar las aguas del río Colca ha sido siempre un factor determinante para la escasez del agua para el riego en el valle. Escasez compartida por todos los pueblos por igual. Si embargo, los grupos humanos que se han asentado en este valle han resuelto el problema de escasez hídrico por otros medios a su alcance. Desde los tiempos iniciales de la cultura de irrigación han utilizado "los ojos de agua" que bajan por las quebradas de ambos lados, para irrigar sus cultivos y sobrevivir con relativa abundancia de recursos de vida. 
Colca es una cuenca interandina que comprende varios pisos ecológicos, que guarda una comprensible unidad, no sólo territorial, sino también hídrico, geográfico, social, económico, cultural (Del Águila, 2008; Alegría, 2008). En lo geográfico-hídrico, la cuenca está integrada por el conjunto de afluentes que discurren sus aguas con dirección a su principal fuente, que va por la profundidad del cañón que lleva el mismo nombre, a la que John Earl (2008) denomina geometría fractal, -concepto propuesto por Beníot Mandelbrot-, aplicado a estructuras complejas que no se pueden explicar con la geometría euclidiana. De acuerdo a la geometría fractal, la estructura de los pequeños afluentes hídricos de la cuenca del Colca, se presenta formalmente irregular, por la conformación de los cerros arrugados, donde no hay líneas rectas, ni círculos, ni cuadrantes regulares. El mismo río central es zigzagueante y su curso toma varias direcciones en sus diferentes partes, por lo que todo es irregular y complejo. Lo que caracteriza a la cuenca del Colca es la forma que asemeja a un árbol de muchas ramas y subramas que se elevan desde el río principal hasta las estribaciones de los nevados. Aquí se puede hablar de cuenca y subcuencas escalonadas, que tributan sus aguas al río Colca. Toda esta red de múltiples entradas va formando a su paso mini cuencas, de acuerdo a la naturaleza de los cerros por donde discurren. Algunas quebradas contienen manantiales de agua y otras no, porque se han formado zanjas con las corrientes de agua durante las temporadas de lluvia. Es este sistema de pequeñas y medianas quebradas, con agua y sin agua, la que caracteriza a la geometría fractal de la cuenca del Colca, que sin lugar a dudas se asemeja a un frondoso árbol desojado de otoño. Con estas pequeñas goteras de agua, socialmente utilizadas, han solucionado la escasez del recurso hídrico.

\section{La infraestructura de riego en el valle}

Canales y reservorios. Ojos de agua, manantiales, chorrillos y pequeños riachuelos por donde corre el agua, son los que los pueblos del valle del Colca han utilizado desde antiguo y la siguen utilizando hasta el presente. Construcción de canales para derivar las aguas y de reservorios para almacenarla ha sido y es la tecnología hidráulica utilizada. Por esta tradición, el riego de los cultivos está sustentado en el aprovechamiento eficiente de estos manantiales. En las tres zonas del valle: alta, media y baja, comprobamos lo que aquí se afirma, sin considerar el riego regulado. Las localidades de la zona alta: Sibayo, Tuti y Canocota, que practican una agricultura limitada, tienen sus propios manantiales para la irrigación de sus campos; las de la zona media: Chivay, Coporaque, Yanque, Maca, Achoma, Ichupampa, Lari y Madrigal; y las de la zona baja: Pinchollo, Cabanaconde, Tapay y Huambo, pueblos predominantemente agrícolas, utilizan las aguas de las minicuencas fractales con mejor eficiencia. En la mayoría de los pueblos hay canales principales y secundarios que salen de los manantiales o de reservorios artificiales, que tienen nombres propios. En casi todos los canales hay uno o más reservorios construidos, según la cantidad de agua que fluye del manantial. Hay en distintas comunidades, pequeños canales que irrigan a pocas parcelas, complementado por un pequeño reservorio. Igualmente, de algunos reservorios, especialmente de los mejorados y ampliados, como en Coporaque, salen canales en varias direcciones, según la ubicación de los terrenos irrigables y la capacidad de riego simultáneo con las aguas empozadas; hay también canales principales de donde se reparte agua a canales secundarios y de éstos a canales terciarios. En cada localidad la red de canales responde a la naturaleza del terreno y a la modalidad de distribución de las parcelas familiares.

En la actualidad, la infraestructura de riego está experimentando importantes cambios tecnológicos, a partir de su estructura tradicional. Hasta los años setentas del siglo 
anterior, los canales de riego y los reservorios construidos desde tiempos de collaguas y cabanas, pasando por la fase de los incas, y lo que se hicieron durante la época colonial y republicana, estaban hechos de material natural: canales y reservorios sobre el suelo, sostenido por tierra y piedras, revestidos de champa, gramínea de raíces que dan consistencia a las paredes de la infraestructura. Las faenas festivas del yarqa aspiy, que se siguen practicando hasta ahora, tenían por objeto recortar las hojas crecidas de las gramíneas, depurar las malezas y hojas secas caídas al canal y al reservorio y quitar las piedras que habían caído sobre los lechos de los canales. El objeto del yarqa aspiy de hoy sigue siendo el mismo, pero cada vez hay menos tramos de canales y reservorios que limpiar. Lo que ha ocurrido desde los años de la reforma agraria es el mejoramiento de la infraestructura de riego, mediante la utilización de material noble: el cemento. El cemento está reemplazando a la champa en los canales de riego y los reservorios. Los principales canales de riego, desde Sibayo a Cabanaconde y Tapay, ya están revestidos con cemento. Mediante la cooperación técnica de las ONG que actúan en el valle y los esfuerzos de las agencias del Gobierno Central y del Gobierno Regional ${ }^{14}$ se han hecho importantes avances en este proceso de mejoramiento de la infraestructura de riego. En esta misma dirección, el Plan Estratégico 2005-2015 del Distrito de Riego Colca-Siguas se ha trazado como objetivo revestir canales y reservorios en casi todas las localidades del valle en un aproximado del $80 \%$ de su infraestructura.

La modernización de canales y reservorios tiene sus efectos en otros procesos de la agricultura del valle: aumento de la capacidad de riego, mejora en la producción de cultivos, readecuación en la cultura del riego, disminución de la principal motivación para los actos simbólicos dedicados al agua de riego. Evidentemente, la capacidad de riego ha mejorado sustancialmente, porque los canales y reservorios revestidos de cemento han disminuido las filtraciones de agua, al mismo tiempo que ha producido mayor correntada en el curso de los canales. No ha aumentado el volumen de agua, que sigue siendo el mismo, lo que ha provocado el revestimiento de canales es el mejor aprovechamiento del agua de riego. Consecuencia inmediata de lo anterior es la mejora en la producción de los sembríos, porque ha aumentado la oportuna asistencia de riego a las sementeras. Algunas siembras como de la alfalfa y las habas requieren de 4 a 5 riegos; mientras que el maíz, la papa, el trigo, se riegan por lo general tres veces antes de las cosechas. Con las mejoras introducidas, los campesinos tienen mejores opciones para salvar sus cosechas por medio del riego oportuno. Por lo mismo, la cultura tradicional de riego se está modificando al ritmo del mejoramiento de la infraestructura. El ciclo de turnos de riego por cada campesino vuelve en menos días; la conducción del agua de riego del reservorio a la chacra es más rápida, por lo que los regadores se ven obligados a modificar sus técnicas para cubrir de humedad a mayor cantidad de andenes o parcelas. Es previsible que a mayor avance de los revestimientos de canales y reservorios tenga también consecuencias en los rituales dedicados al agua. Aún no se producen estos cambios, pero cuando ya no haya canales y reservorios que limpiar y reparar, habrá menos motivos para continuar practicando los rituales del agua. Por esta razón, en algunas poblaciones se resisten a la modernización. El entubado de los canales con materiales de poliotileno y de plástico, es un nuevo elemento tecnológico que ya se viene aplicando en algunas poblaciones. Forma parte del Plan Estratégico de la Junta de Usuarios con sede en Chivay.

14 Foncodes es una de las agencias del Gobierno, además de otras, que mejor contribuye en canalizar con cemento las acequias y estanques del valle; el Gobierno Regional de Arequipa viene invirtiendo, igualmente, considerables fondos dedicados al mejoramiento del riego de esta provincia. 


\section{La organización social del riego: lo tradicional y lo moderno}

En el Perú han funcionado históricamente varios modelos de organización social del riego. Probablemente, la forma cómo los incas organizaron este sistema racional ha sido el mejor implementado en la sociedad andina. En ese entonces, la agricultura fue la base económica de la sociedad, gracias a una rígida estructura productiva de cultivos y una coherente administración del agua de riego. Colosales canales y reservorios construidos socialmente a lo largo del territorio andino y una organización centralizada del Estado, que delegaba sus funciones jerárquicamente hasta el nivel de los curacas locales (Alfaro, et al, 1993; Regal, 2005; Alegría, 2007). Un territorio tan hostil como los Andes, requería necesariamente de un régimen autoritario y planificado para vencer los obstáculos que la geografía, la escasez de recursos hídricos y breves temporadas de lluvias, requería de una política planificada desde el Estado. Pero este alto desarrollo tecnológico de la agricultura prehispánica, sustentado en un eficiente sistema de riego, se resquebraja durante la colonia, modelo político que privilegió la utilización de mano de obra en las explotaciones mineras, obrajes, edificación de iglesias y mansiones. Todo el andamiaje productivo construido por los incas se deteriora y los campos agrícolas de costa y sierra y la infraestructura de riego sufren un rápido colapso. El régimen colonial implementa su propia organización social del riego, con las normas que se dictan desde la metrópoli (Leyes de Indias). Fruto de estas leyes son los Regidores de Agua y todo el sistema de autoridades de vara (varayoc), que se encargaron de resolver los problemas del riego y de otros aspectos de la actividad agrícola y ganadera de las reducciones de indios. En varias regiones del país, este sistema de autoridades ha prevalecido durante la República y prevalece aún hasta nuestros días ${ }^{15}$.

De los varayoc a las Comisiones de Regantes. Los varayoc se mantuvieron durante la República en sus papeles administrativos locales de las poblaciones rurales y, a falta de injerencia directriz del Estado, la administración de las aguas de riego recayeron en los Regidores de agua que también se llamaban jueces de agua, que continuaron en este papel tradicional hasta 1969. Los distintos decretos que se dan en el siglo XIX y la creación de la Dirección de Aguas que promulga el gobierno central en 1911, favorecen y privilegian directamente a los intereses de los terratenientes. Los pequeños parceleros y las comunidades indígenas de entonces han estado desprotegidas por el Estado (Bonilla, 1987; Montoya, 1989). Sin embargo, el trato de exclusión a las comunidades, dio lugar para que en ellas se mantuviera el control y la distribución de las aguas de riego en manos de los jueces de agua. En ese estado lo encontramos en la década de la Reforma Agraria, 1969-1980.

Con la reforma agraria dirigida por el Gral. Juan Velasco Alvarado llega la modernidad en el sistema de riego a nivel nacional. El gobierno militar de entonces no sólo promulga el Decreto Ley $\mathrm{N}^{\mathrm{o}}$ 17716, en fecha simbólica del 24 de junio de 1969 , con la que afecta a las grandes y medianas propiedades en manos de los tradicionales terratenientes ${ }^{16}$, pone en marcha también la Nueva Ley de Aguas, con el Decreto Ley $\mathrm{N}^{\mathrm{o}} 17752$ que sale el 24 de julio de 1969. Esta normativa sobre el agua, que reemplaza a la vetusta ley de 1911, declara en su Art. $1^{\circ}$ que, "Las aguas, sin excepción alguna, son de propiedad del Estado y su dominio es inalienable e imprescriptible". A partir de

15 En los pueblos de Huarochirí, estudiados, por Tello y Miranda, Llanos y Osterling, Gelles, Vargas y otros, las autoridades de vara siguen teniendo papeles importantes en el sistema de riego.

16 Con esta nueva ley de reforma agraria, la tercera que se da en la década del sesenta, desaparece de la escena nacional la clase terrateniente, que durante la vida republicana mantuvo el control de la propiedad de la tierra y a través de él el manejo político civil-militar del Estado (Ver: Matos Mar y Mejía, 1980). 
este primer enunciado, reordena la administración centralizada de todas las aguas, según su uso, desde el aparato estatal y establece los objetivos, funciones y mecanismos de regulación del sistema de distribución de este recurso natural en lo pertinente a las aguas de riego, a través de funcionarios legalmente nominados y reconocidos. El Ministerio de Agricultura y Pesquería es el organismo rector en esta materia. Se crean, a lo largo y ancho del país, sectorizado en Zonas Agrarias, las Administraciones Técnicas de los Distritos de Riego, en calidad de entes operativos con funciones de ordenamiento, planificación, administración y solución de problemas derivados del uso social de las aguas de riego agrícola. En la jurisdicción de cada Distrito de Riego se reconocen a las Comisiones de Regantes de cada localidad, elegidos por los usuarios, por períodos de dos años y reconocidos por los Distritos de Riego. En los casos necesarios, se nombran Comités de Regantes, con papeles específicos para sectores y subsectores de localidades y comunidades campesinas. Las Comisiones de Regantes lo conforman ocho miembros: Presidente, Vicepresidente, secretario, tesorero, fiscal, dos vocales y el regidor de aguas. En la práctica, es el regidor de aguas el que maneja la distribución del agua de riego, con el respaldo orgánico de la Comisión de Regantes (Ley 17752). Este sistema de organización, con algunas modificaciones introducidas hasta finales del siglo anterior, es el que está funcionando en el valle del Colca y en todo el país. El gobierno actual ha promulgado recientemente una nueva Ley de Recursos Hídricos, dada por el Congreso, identificada con el No 29338, a la que deberá adecuarse el sistema de riego en el Perú ${ }^{17}$, sustituyendo a la ley anterior. Esta ley establece nuevos agentes en la administración del agua de riego agrícola y nuevos mecanismos de distribución, que no lo comentamos por obvias razones.

Organización del riego en el valle de Colca. Hasta mediados del 2009, la organización del sistema de riego en el valle del Colca funcionaba como manda la Ley de Aguas $\mathrm{N}^{\mathbf{0}}$ 17752, su Reglamento y normas conexas. Pertenece a la Región Agraria de Arequipa y al Distrito de Riego Colca-Siguas. El Distrito de Riego incluye a la macro cuenca ColcaMajes-Camaná, desde las altas punas de Condoroma hasta el valle costeño de Camaná que colinda con el océano Pacífico. La parte propiamente del valle de Colca está bajo la jurisdicción del Subdistrito de Riego del Colca, que tiene su sede en Chivay y administra a todas las poblaciones que aparecen en los cuadros que acompañan al presente trabajo. Para los fines de su mejor operatividad, el Sub-distrito de Riego del Colca considera cuatro sectores de riego dentro de su ámbito: Condoroma, Chivay, Lari y Cabanaconde. A su vez, dentro del Subdistrito existen 31 Comisiones de Regantes que aparecen en los cuadros $\mathrm{N}^{\circ} 2$ y $\mathrm{N}^{\circ} 5$. De ellos, 19 comisiones corresponden a localidades de la margen izquierda, que disponen de 6918.89 Ha de tierras bajo riego, distribuidos en 20728 predios para 4140 usuarios y otras 12 comisiones pertenecen a pueblos de la margen derecha, con un área de $2720.35 \mathrm{Ha}$, un total de 12175 predios, distribuidos a 2167 usuarios (Diagnóstico de la Junta de Usuarios, 2008). Hay además en el valle 11 Comités de Riego ${ }^{18}$, reconocidos por el Distrito de Riego: Quenco Cala Cala, Cauca, La Esperanza, Paque Cantera Alta, Palacchilla, Ucuchachas, Sangalli, Anansaya I, Anansaya II, Llactosayaña y Fure Tocallo.

17 La ley No 29338 fue promulgado el 30 de marzo del 2009 y su aplicación está todavía pendiente. Diversos sectores de la sociedad, entre ellos los campesinos del sur peruano, cuestionan esta norma por ser privatista y atentatoria a los derechos de uso del campesinado en general.

18 La diferencia de Comisiones de Regantes y Comités de Riego consiste en que los primeros son organismos implementados en poblaciones estables con larga tradición de riego y los sectores de riego que se favorecieron con las aguas del proyecto Majes, mientras que los Comités de Riego son organismos específico que se van creando cuando se aperturan nuevas fronteras agrícolas o proyectos de irrigación, dentro o fuera de las organizaciones comunales. 
Cuadro $\mathbf{N}^{\circ}$ 5. Fuentes de agua e infraestructura de riego: valle del Colca

\begin{tabular}{|c|c|c|c|c|c|}
\hline $\mathbf{N}^{0}$ & Comisiones de regantes & Manantiales & Válvulas & Canales & Reserv. \\
\hline 1 & Achoma Anansaya & 5 manantiales & 5 válvulas & 5 & 5 \\
\hline 2 & Achoma Urinsaya & 10 manantials & 2 válvulas & 3 & 5 \\
\hline 3 & Canocota & 4 manantiales & 1 válvula & 2 & 2 \\
\hline 4 & Chivay Anansaya & 3 manantiales & 1 válvula & 3 & 2 \\
\hline 5 & Chivay Ccapa & 3 manantiales & 2 válvulas & 2 & \\
\hline 6 & Chivay Urinsaya & 2 manantiales & 1 válvula & 3 & 1 \\
\hline 7 & Madrigal & 7 manantiales & & 3 & 3 \\
\hline 8 & Sibayo & 2 manantiales & & 1 & 2 \\
\hline 9 & Lari & 10 manantials & & 2 & 5 \\
\hline 10 & Llanca & 2 manantiales & & 2 & 3 \\
\hline 11 & Tuti & 3 manantiales & & 2 & 4 \\
\hline 12 & Coporaque & 10 manantials & & 5 & 5 \\
\hline 13 & Cosñirhua Malata & 3 manantiales & & 2 & 3 \\
\hline 14 & Tapay & 1 manantial & & 2 & 3 \\
\hline 15 & San Juan de Chuccho & 3 manantiales & & 1 & 2 \\
\hline 16 & Huambo Campiña & & & 1 & 4 \\
\hline 17 & Huambo Chininí & & 1 válvula & 1 & 1 \\
\hline 18 & Huambo Zona Regulada & & 1 válvula & 2 & \\
\hline 19 & Ichupampa & 4 manantiales & & 2 & 5 \\
\hline 20 & Llatica & 3 manantiales & & 3 & \\
\hline 21 & Maca Anansaya & 12 manantials & 2 válvulas & 1 & 2 \\
\hline 22 & Maca Urinsaya & 10 manantials & 1 válvula & 1 & 5 \\
\hline 23 & Yanque Anansaya & 2 manantiales & 1 válvula & 1 & 5 \\
\hline 24 & Yanque Urinsaya & 1 manantial & 1 válvula & 1 & 2 \\
\hline 25 & Pinchollo & 1 manantial & 2 válvulas & 3 & \\
\hline 26 & Cabanaconde Campiña & 1 manantial & 1 válvula & 3 & 2 \\
\hline 27 & Castropampa & & 1 válvula & 1 & 1 \\
\hline 28 & Las Joyas & 1 manantial & & 1 & 1 \\
\hline 29 & Media Luna & & 1 válvula & 1 & 1 \\
\hline 30 & Villa el Colca & & 1 válvula & 1 & \\
\hline 31 & Acpi & & 1 válvula & 1 & \\
\hline & Totales & 103 fuentes & 26 válvuls & 62 & 74 \\
\hline
\end{tabular}

Fuente: Cuadro confeccionado con los datos de la Junta de Usuarios, 2008.

Tanto las Comisiones de Regantes como los Comités de Riego son organismos locales en directa interdependencia con el Subdistrito de Riego. En el nivel interno, las Comisiones y los comités nombran por rotación uno o más regidores de agua. El papel específico de los regidores o yaku alcaldes, como lo denominan en este valle, es distribuir las aguas de riego, ya sea en todo el ámbito de la comunidad o irrigación o en forma descentralizada, 
por canales o sectores de riego, según los casos específicos. Cada regidor lleva un libro con la lista de los usuarios y la rotación de turnos que les corresponde. En el reparto de turnos de agua no hay normas fijas preestablecidas. Se entiende que los turnos se rotan en orden regular para todos los usuarios; sin embargo, la realidad de cada pueblo es distinta y los regidores aplican sus mejores criterios en la distribución o ceden a la presión de los usuarios más poderosos. Por la ausencia de una normatividad precisa, los problemas de reparto de turnos se agudizan a medida que llega el tiempo de escasez de agua. En estos casos, los días de reparto de turnos, domingos o lunes, según la costumbre de cada comunidad, son sesiones de alterados conflictos verbales, donde "los mayoristas" (usuarios con mayor cantidad de parcelas) consiguen más mitas de agua, apelando a diversos argumentos, en perjuicio de los derechos de mita o turno de los usuarios "minoristas" (con pocas parcelas). Estos problemas se agudizan en localidades con varios sectores de riego y varios canales principales y secundarios, asociados a cultivos de distintos productos en pisos ecológicos diversos por cada familia. Los usuarios deben lidiar ante el regidor por sus turnos de agua en cada sector o cada toma de agua. Cada turno está en directa relación con la extensión del cultivo. En el valle, las extensiones de las parcelas se miden por topos ${ }^{19}$ y cada topo tiene su turno correspondiente. Por el minifundismo acentuado, el mayor porcentaje de parcelas mide de uno a dos topos, pero los "mayoristas" tienen propiedades que superan los diez topos, situados en distintas altitudes. Por estas desigualdades en la tenencia de la tierra, la influencia que ejercen los pudientes, asociado a la escasez de agua, la distribución de mitas en cada pueblo es un problema continuo. Asistir a las sesiones de distribución de mitas y revisar los cuadernos que usan los yaku alcaldes son temas interesantísimos, que aún no ha merecido atención de los investigadores sociales.

Por otro lado, funciona en el valle una Junta de Usuarios, que agrupa al conjunto de Comisiones de Regantes y Comités de Riego, así como a tres localidades de la provincia de Castilla: distrito de Choco, anexos de Llanca y Ucuchachas, ubicadas río abajo. Esta Junta fue fundada en julio de 1981 y alcanzó reconocimiento legal en diciembre de 1993, al amparo de las normas legales pertinentes. Tiene su directiva y su propio aparato administrativo, bajo la dirección de un gerente técnico. Su función es la de monitorear la correcta administración del riego agrícola, fortalecer a las Comisiones de Regantes y Comités de Riego, dirigir las campañas agrícolas y de impulsar proyectos de mejoramiento de la infraestructura de riego en pro del desarrollo agrícola. Con la finalidad de lograr sus metas, la Junta de Usuarios coordina acciones, directamente o a través de convenios con distintas entidades públicas, como con las dependencias del Ministerio de Agricultura, municipios y también con entidades no gubernamentales que operan en el valle ${ }^{20}$. En su calidad de organismo promotor, se encarga de organizar una serie de eventos orientados a dinamizar el desarrollo agropecuario y la comercialización de productos de las familias campesinas: ferias agrícolas, ferias pecuarias, encuentros de las Comisiones de Regantes ${ }^{21}$, con la participación y auspicio de diversas instituciones públicas y privadas. Esta Junta no interviene en la distribución de las aguas que es potestad de los yaku alcaldes.

19 El topo es una medida agraria del incanato. En el Colca, la extensión de un topo es igual a un tercio de hectárea, es decir aproximadamente a $3333 \mathrm{~m}^{2}$. En San Pedro de Casta, un topo equivale al trabajo de un campesino, en un día, con herramienta tradicional, la chaquitaklla.

20 DESCO es una de las ONG que ha intervenido en proyectos de desarrollo pecuario, agrícola y mejoramiento de infraestructura, desde los años ochenta; en la actualidad hay otras ONG como Sierra Sur, Araucaria, Asde, además de instituciones públicas como Foncodes, Pronamachcs, Autocolca, Autodema y municipio provincial y distritales, que tienen sus propios proyectos.

21 Hasta el año 2008 se han organizado veinte Encuentros de Comisiones de Regantes, con un mínimo de tres días de duración y con un nutrido programa de actividades ampliamente publicitadas. 
Fuentes del recurso hídrico. En la autorizada opinión de la gerencia de la Junta de Usuarios, el recurso hídrico es deficitario para la agricultura en el valle. Lo es fundamentalmente porque los agricultores de estos pueblos no utilizan las aguas del río Colca, riegan sólo con las aguas de los manantiales y riachuelos que discurren de ambos lados de la cordillera. Este déficit mejoró, con el parcial aprovechamiento de las aguas del proyecto Majes, que data de los años setenta; pero estas aguas sólo benefician a los agricultores de la margen izquierda. El canal Tuti-Majes capta $15.0 \mathrm{~m}^{3} / \mathrm{s}$ y provee a las comunidades del valle un caudal de $1.4 \mathrm{~m}^{3} / \mathrm{s}$. Contribuyó también a mejorar el riego, la construcción de cuatro mini represas: Tuti, Sibayo, Yanque y Lari. Un recuento cuantitativo, aproximado a la realidad actual del valle, de las fuentes de agua y de la infraestructura de riego, lo vemos mejor en el cuadro $\mathrm{N}^{\circ}$ 5. En la actualidad, el sistema de riego en el valle se ejecuta por tres modalidades, según la clasificación técnica: a) riego no regulado, con las aguas de manantiales y riachuelos naturales; b) riego regulado, con las aguas del proyecto Majes; y c) el riego mixto o combinado, con aguas de ambas fuentes. Evidentemente, el flujo fijo de disponibilidad hídrica para el riego lo proporciona el canal Tuti.Majes, del que las comunidades hacen uso regulado, a través de 26 válvulas, distribuidas en los territorios de Chivay, Yanque, Achoma, Maca, Pinchollo, Cabanaconde y Huambo. Según la Junta de Usuarios, el caudal total de agua para el riego que disponen en el valle asciende a 4605.85 1/s. De esta cantidad, 2,536.10 1/s se captan de los manantiales; otros $715.75 \mathrm{l} / \mathrm{s}$ vienen del río y los nevados; y 1354.00 1/s son las aguas reguladas del canal de Majes.

Por sus características, el riego en este valle es de lo más peculiar: funciona un sistema combinado de opciones que lindan entre lo tradicional y lo moderno. Por un lado, a lo largo del valle, los agricultores captan el líquido elemento desde 103 fuentes naturales, que son los riachuelos, manantiales y ojos de agua. Ocurre que en los territorios de tan pocos pueblos haya tantos manantiales. En localidades como Maca Anansaya y Urinsaya, Coporaque y Achoma Anansaya hay diez o más de diez, mientras que en la mayoría de las comunidades hay de uno a cinco manantiales. Son por estas "lágrimas de la madre naturaleza", como dice un campesino de Coporaque, que la agricultura ha florecido desde tiempos muy antiguos. Captando la poca agua de estos manantiales, mediante ingeniosos canales, la han conducido hasta la tierra cultivable y hasta los múltiples andenes de cada asentamiento humano. Y para controlar mejor el agua de riego, han sabido almacenarla en reservorios especialmente construidos en las tomas de agua y en los trayectos de canales de largo recorrido. Por esta sabiduría tradicional, los canales de riego siempre están asociados a los reservorios. Sólo esta asociación tecnológica logró desarrollar una eficiente agricultura desde los tiempos prehispánicos y continúa manteniéndola hasta nuestros días.

En el valle del Colca se registran 62 canales y 74 reservorios, que se distribuyen en los ámbitos territoriales de 31 Comisiones de Regantes. La mayor cantidad de reservorios demuestra que las pocas aguas de los manantiales requieren necesariamente del almacenamiento antes del riego. Buena parte de esta infraestructura está entrando a la fase de la modernidad, por el proceso de revestimiento con cemento de los canales principales y de los reservorios, que la hacen más eficientes y seguros. Pero también se han construido nuevos canales y nuevos reservorios en irrigaciones recientes. Con ellos se ha enriquecido la infraestructura tradicional. Lo moderno ha llegado al valle, fundamentalmente por los efectos del Proyecto Majes. A lo largo del recorrido del canal a Majes, por más de $100 \mathrm{Km}$ de distancia, se han abierto las 26 ventanas, donde se han instalado 26 válvulas para regular el agua para las comunidades. Esta concesión de la Autoridad Autónoma del Proyecto Majes ha mejorado la producción agrícola de los pueblos beneficiarios, permitiéndoles 
el riego de sus sementeras sin la tradicional merma del volumen de agua. En la mayoría de los casos, los agricultores han potenciado los canales y reservorios y algunos de ellos no tiene necesidad de hacerlo, pueden usar el agua sólo cuando lo necesitan. Por esta innovación, Cabanaconde produce el mejor y la mayor cantidad de maíz "cabanita" en sus ricas tierras de Campiña, sin el riesgo de perder cosechas por temporadas de sequía; otros pueblos como Chivay, Yanque Anansaya, Maca Anansaya y Urinsaya, Achoma Anansaya y Urinsaya, Pinchollo y Huambo, producen alfalfa permanentemente para fomentar la producción ganadera y tienen buenas cosechas de papas, trigo, cebada, quinua y otros productos, si es que el hielo u otras plagas no los afectan. "Hemos mejorado con el riego regulado pero el agua sigue siendo deficitario", afirma el técnico de Chivay.

Mitas y calendario agrícola. Existen diferentes problemas derivados de la distribución de las aguas, que dependen de las temporadas de abundancia y de escasez y del calendario agrícola que practican los agricultores. Durante los meses de lluvia, de enero a abril, la distribución de los turnos de agua no confronta problemas, a menos que sean años de sequía. Durante esos meses, el riego de sementeras en su proceso de crecimiento, lo hacen sin restricciones. Cuando la lluvia es continua e intensiva, no necesitan irrigar, con la humedad que provee la lluvia es suficiente. Los tres meses siguientes, de mayo a julio, se producen algunos problemas menores en la distribución de los turnos, por el comienzo del estiaje, donde las aguas de los riachuelos y manantiales comienzan a mermar lentamente, por lo que el control en la distribución comienza a racionalizarse. Se agudizan los problemas durante los meses de agosto a diciembre, cuando los acuíferos han disminuido su caudal significativamente. Agosto, setiembre y octubre son meses dedicados a la preparación de terrenos y a la consecuente siembra, con la que comienza el calendario agrícola. Una vez sembradas las sementeras necesitan asistencia de riego. Es durante esta temporada de estío, de agosto a diciembre, donde la distribución de turnos se torna en problema.

El derecho tradicional de mitas de los usuarios del valle contribuye a dificultar la eficiencia en el riego. Es la costumbre denominada "Pedido de agua hasta acabar". Quiere decir que, en estas comunidades, las familias dedicadas a la agricultura tienen derecho de riego, por el tiempo que la parcela necesita ser irrigada hasta terminar. En estos casos, no funciona el tiempo fijo por cada turno (horas o días), lo determinante es el tamaño del predio por irrigar. A mayor escasez del recurso hídrico mayor tiempo para irrigar hasta terminar con la chacra; entretanto, otras sementeras esperan lánguidas el líquido elemento. Esta tradición se complica aún más, cuando cada familia tiene parcelas en distintos pisos ecológicos y cultivos diferenciados, que suponen solicitar mitas para cada canal o sector. $\mathrm{Si}$ a este problema se le agrega otro, como el de favorecer a unos y no mantener la equidad en las mitas, los problemas se multiplican. La Junta de Usuarios no ha entrado a ordenar este sistema tradicional de reparto, ni tiene autoridad para hacerlo. La nueva Ley de Recursos Hídricos puede que lo solucione, pero requerirá de un buen tiempo para logarlo, si es que se aplica un nuevo ordenamiento en la distribución de turnos, que sea más justo y funcional. Sin embargo, entre la ley que fenece y la ley que entra, hay pocas diferencias. La nueva ley implementa en las localidades de cada cuenca a la Junta de Usuarios; debajo de esta Junta están las Comisiones de Usuarios, y en cada fuente hídrica específica o canal de riego sitúa a los Comités de Usuarios (Art. 28, 29 y 30). Es decir, un cambio de términos, que el Reglamento deberá precisar. Del sistema de mitas no hay nada nuevo.

Por histórica tradición, los agricultores de este valle practican exclusivamente el riego por inundación, denominado también "riego por gravedad". Esta es probablemente la modalidad con que comenzó la cultura del riego agrícola y en más de dos milenios no 
ha cambiado mucho ${ }^{22}$. En el valle del Colca, el riego por gravedad está tecnificado por conocimiento tradicional, por la existencia de espacios agrícolas mayoritariamente en terraplenes artificiales. Por esta especial realidad, los agricultores están especializados en riego de filigrana. Los estrechos espacios de cultivos requieren de un manejo muy cuidadoso y preciso, teniendo en cuenta no deteriorar los andenes por exceso de inundaciones. Desde antiguo, no sólo los terrenos cultivables de los andenes están debidamente adecuados para la circulación del agua por gravedad, sino también, los canales de riego y los surcos trazados por la chaquitaklla o por el arado, están hechos de tal manera que el agua de riego puede circular eficientemente. A esta forma de manejo de la tierra y del agua están acostumbrados los campesinos, por generaciones sucesivas y se resisten en adoptar nuevas técnicas de riego. La Junta de Usuarios, los técnicos de Pronamaches ${ }^{23}$ y las ONG promotoras del desarrollo agropecuario han intentado introducir el riego por goteo y por aspersión; no han tenido éxito, "por la indiferencia y la resistencia por cambiar sus costumbres".

\section{Ceremonias tradicionales vinculadas con el riego}

"Los pueblos indígenas "pertenecen" profundamente a un territorio. En ese territorio se ha escrito su historia, su modo de vida y una compleja red de símbolos ligados a lugares sagrados llegando a ser un "sujeto espiritual", un lugar "caminado, sembrado y sacralizado"...", expresa el documento de CEPAL (2007), cuando se refiere a la relación de los pueblos indígenas y al territorio donde habitan. Interpreta así la cosmovisión de los pueblos originarios. En efecto, allí están las historias de sus vidas sociales, de sus luchas, de sus problemas, de sus bondades, de sus éxitos, de sus frutos. Por ser así de profunda la ligazón del hombre con su hábitat, ama a la tierra, la defiende, la idolatra, la sacraliza (Millones, et al., 1994; Regal, 1970; Valderrama y Escalante, 1988). En más de cinco siglos de dominación europea, la historia de los pueblos de América del Sur han pasado de la situación colonial a la de emancipación y de ésta a la formación de repúblicas, gobernados por una minoría de criollos, casi siempre bajo la tutela de las potencias europeas y norteamericana, pero sobre todo bajo la adopción de la racionalidad dominante venida de occidente. Al interior de estas repúblicas que ya tienen cerca de dos siglos, subsisten diversos grupos originarios que tienen sus propios modos de vida, formas culturales específicas, lenguas nativas y propia filosofía de vida. Para el campesino andino, las montañas y cerros (Wamanis) apus que lo rodean, las lagunas, los ríos, tienen vida y tienen poderes; por eso dialogan con ellos para mantener correspondencia recíproca. El hombre no es sino un ser vivo más, como los animales y las plantas, que espera de los poderes de la naturaleza sagrada beneficios para su propia existencia. Es en este universo de pueblos originarios donde funciona como herencia cultural la cosmovisión de que el hombre es parte indesligable del territorio, de la madre naturaleza en la que habita. La respeta y le rinde pleitesía para alcanzar los beneficios que necesita. Esta es la otra forma de creencia religiosa, de data prehispánica, que convive hasta estos tiempos con la fe cristiana (Fuenzalida, 1977; CEPAL, 2007; Arroyo, 2008).

Para el espacio andino hay abundante literatura sobre este tema. Probablemente, los relatos orales en quechua recogidos por Francisco de Ávila y traducidos al castellano en Dioses y hombres de Huarochiri por José María Arguedas y en Ritos y tradiciones de Huarochirí por Gerald Taylor, es la versión más antigua sobre la simbolización y sacralización

22 En las poblaciones tradicionales de todo el país, se sigue practicando el riego por gravedad; las formas modernas del riego corresponden a los agricultores de la costa y a las nuevas irrigaciones.

23 El Programa Nacional de Manejo de Cuencas Hidrográficas y Conservación de Suelos (Pronamachcs), es una dependencia del Ministerio de Agricultura en el Perú. 
de las montañas y los rituales dedicados a ellas. Cronistas como Inca Garcilaso, Cieza de León, Felipe Huaman Poma y otros dan cuenta de las tradiciones, que durante el incanato se practicaban ofreciendo ofrendas en honor a las montañas, manantiales, la lluvia. Entre los estudiosos modernos, Tello y Miranda (1923) relatan en detalle los rituales dedicados a Wallallo en la fiesta del agua en la comunidad de San Pedro de Casta, situado a sólo 90 $\mathrm{km}$ de Lima. Wallallo aparece aquí como una deidad gentilicia fundadora de la agricultura de riego, con un sistema de canales y reservorios, que los casteños limpian anualmente, al mismo tiempo que rinden tributo a su progenitor originario, a sus cerros sagrados, al agua y a la lluvia, en sendas ceremonias muy bien organizadas socialmente, por barrios que representan a los ayllus y a su simbología. Carrión (1955) se ocupó de dar énfasis del culto al agua en el antiguo Perú a través de las pacchas (caídas de agua) simbolizadas en ceramios y esculturas de madera en las distintas culturas preíncas e inca; así como también Regal (1970) estudia los trabajos hidráulicos de los incas, donde la tecnología de riego está íntimamente imbricada a la ideología simbólica de la sacralización de los elementos naturales propiciatorios del agua. Otros estudiosos más recientes, como Llanos y Osterling (1986), Gelles (1986), se ocupan de estudiar los cambios y permanencias de la fiesta del agua y dan versiones nuevas sobre los rituales dedicados al agua en Casta. Para la región de Ayacucho hay otros estudios sobre lo mismo. El que publicara Arguedas (1964) para el caso de Puquio, como también los trabajos de Valiente (1989), de Bendezú (1990), sitúan sus trabajos en Ayacucho, mientras que Farfán (2002) lo hace para la comunidad de Huaros en el valle de Canta. Tanto los trabajos de limpieza como los rituales en Huaros se realizan en oposición complementaria de anan y urín e involucran a sus dos cuencas y canales principales (Millpo y Jaguajo), que tienen origen en los nevados de Auquichani y las lagunas naturales de Chilhuacocha (Anan), Jacrash y Yanauya (Urin), sus huacas sagradas y los espacios ceremoniales correspondientes a cada barrio. Lo resumido hasta aquí es sólo una muestra de la literatura diversa, antigua y moderna, que da cuenta de la vigencia de la sacralidad del agua, de la lluvia, de las lagunas y de las montañas que rodean a las sociedades agricultoras en distintas regiones del ande peruano.

Los pueblos del valle del Colca son partícipes de esta forma de pensamiento mítico religioso hombre-naturaleza, en concordancia con su propia cosmovisión; practican sus propias costumbres y sus formas de vida, hablan quechua y castellano y son creyentes en sus deidades naturales como herencia de sus antepasados prehispánicos y también en los símbolos del cristianismo que viene por la influencia colonial. Están situados en un territorio agreste y difícil de dominar, en un valle profundamente empinado y cortado por la fuerza de las aguas. Para habitarla y convertirla en tierra productiva, la mano y la creatividad del hombre han construido andenes sobre las laderas, con la tierra necesaria para producir cosechas de plantas domesticadas. Por su ubicación, es una microrregión dependiente de los deshielos de las altas montañas que la circundan, como también es dependiente de las bondades de la madre naturaleza, que en sus temporadas de lluvia le proveen de suficiente recurso hídrico para garantizar buenas cosechas. Sobre la tierra ha ejercido control y dominio, mediante la implementación de los cultivos, utilizando tecnología construida con sus manos (taklla, chaquitaklla, azada, arado) y también la fuerza animal ${ }^{24}$. Para asistir con riego a sus sementeras ha construido canales desde los ríos y manantiales, para almacenar y controlar el riego socialmente regulado ha construido reservorios. El arte para adecuar la tierra para el cultivo y la ingeniería para irrigar esas tierras es la maravilla de la cultura agrícola del valle. Lo que no tienen dominio los habitantes del Colca es sobre el agua. Son otros factores de la naturaleza los que permiten la abundancia o la escasez del agua para el

24 En Cabanaconde y otros pueblos del valle se usan bueyes, mulos y burros como animales de tiro. 
consumo y para el riego. La lluvia estacional es la que riega los campos; el granizo, la nieve y el viento frío mantiene níveo a las altas montañas de ambos lados del valle, de donde se originan los ríos que dan sus aguas a otros ríos mayores de la cuenca del Pacífico y de la Amazonía.

Desde los tiempos que se inventó la agricultura en este valle tienen carácter sagrado las principales montañas nevadas de su entorno: el nevado Mismi $(5597 \mathrm{msnm})$ por el norte, deidad principal de los pueblos de Coporaque, Yanque, Ichupampa, Lari, Madrigal y Tapay, al que se incluye por su ubicación a los glaciares de Quehuisha y Gulluncuya; el nevado Hualca Hualca (6023 msnm) situado al suroeste, para los pueblos de Cabanaconde, Pinchollo y Huambo, al que se incluye por estar en esa dirección a los nevados de Sabancaya y Ampato $^{25}$ (6318 msnm). Chivay cuenta con dos glaciares emblemáticos: Huarancante (5200 msnm) y Hornillo. Los pueblos de Yanque Hanan Saya, Maca y Achoma, situados también en el lado izquierdo del río, no colindan con montañas nevadas, por lo que sus deidades son montañas sin nieve que tienen distintos nombres, de donde discurren las aguas para el riego. A su vez, cada localidad tiene sus propios manantiales, que también tienen carácter sagrado, por ser la pacarina, origen de las aguas de riego. Además de las montañas nevadas, constituyen también deidades menores, los cerros específicos de cada pueblo, de cuyas quebradas brotan pequeñas fuentes de agua. Todos ellos reciben ofrendas y "pagos" simbólicos en las fechas preestablecidas por la costumbre, en señal de reciprocidad. En el pensamiento religioso andino de esta región, las montañas y los cerros cercanos son los que "dan sus aguas" a los habitantes de la región. En reciprocidad por este don, les deben pleitesía y "pagos especiales", que se efectúan en ceremonias debidamente instituidas desde tiempos inmemoriales. Las montañas con nieves perpetuas o sin ellas son deidades pródigas con el agua, siempre que haya buenas lluvias estacionales. Las temporadas de lluvias no sólo mantienen el cúmulo de nieve en las altas montañas, sino también humedecen suficientemente a los cerros para que esa humedad mantenga el fluir de los manantiales. Para preservar la suficiente humedad, los campesinos del Colca y de otras regiones del Perú hacen "emborrachar" a los cerros altos, mediante el tendido de agua de lluvia por canales construidos expresamente en zonas altas, sólo para provocar la humedad ${ }^{26}$. Las discontinuidades de la naturaleza han exigido históricamente al hombre andino a recurrir a varias estrategias para la provisión del agua de riego: las estrategias concretas de la ingeniería hidráulica y de la construcción de una ideología concomitante con la creencia en divinidades sacralizadas de su pensamiento religioso.

\section{La fiesta del agua y los rituales propiciatorios}

Ritos y faenas colectivas andan juntos en la memoria y en las tradiciones dedicadas al culto del agua. Estas costumbres constituyen actividades anuales muy antiguas: consiste en la convocatoria de los usuarios para reparar, limpiar y adecuar convenientemente la infraestructura de riego de cada unidad poblacional, mediante faenas colectivas y ritos dedicados a las deidades. A esta arraigada tradición, que funciona en casi todo el territorio andino, se le denomina en el valle del Colca: yarqa aspiy, o escarbe de acequias (limpiar las

25 En 1996 los arqueólogos Miguel Zárate y Juhan Rienhard encontraron en el nevado Ampato los restos de "Juanita", que hoy se conoce como La dama de Ampato, cuyo cuerpo habría sido sacrificado al Wamani en una ceremonia inca de Capacocha.

26 En San Andrés de Tupicocha (Huarochirí) se denominan Amunas al sistema de recarga de humedad de los cerros de la puna, con la finalidad profundizar la humedad y mantener el flujo de los manantiales. Es una técnica de mantenimiento de humedad provocada artificialmente, de origen prehispánico, que en muchos lugares ha entrado en desuso. 
acequias) ${ }^{27}$. Las fechas de estas convocatorias dependen de cada población. Por lo general, en los pueblos del valle del Colca se realizan varias faenas durante el año: la primera lo realizan en diciembre cuando comienzan las lluvias, la segunda durante los carnavales y la tercera, que es la principal, lo hacen entre julio y agosto. En otras regiones, la fecha de la fiesta principal del agua, se realizan desde febrero a diciembre, es decir, desde la temporada de lluvias hasta la aparición de las lluvias primerizas de la siguiente temporada ${ }^{28}$. Para los campesinos, el yarqa aspiy es un acontecimiento colectivo que involucra a todos los comuneros y parceleros, que son los usuarios de las aguas de riego (Tello y Miranda, 1923; Carrión, 1955: Arguedas, 1964; Fonseca, 1983; Llanos y Osterling, 1986; Gelles, 1986; Millones y Onuki, 1994).

Organización del yarqa aspiy. La limpieza ceremonial de los canales y reservorios de los pueblos del valle del Colca es una actividad eminentemente comunal. Es así porque es la comunidad campesina, debidamente organizada y reconocida, la que controla en general los recursos de la tierra y del agua, aun cuando en su interior prevalece la propiedad privada familiar de las parcelas bajo riego. Por disposición de la anterior Ley de Aguas, la administración de las aguas de riego recae en las Comisiones de Regantes, cuyos responsables se nombran entre los comuneros usuarios de cada localidad. Por esta particularidad, la faena festiva del yarqa aspiy se realiza bajo la administración de las Comisiones de Regantes, que a su vez dependen de las comunidades campesinas respectivas. El otro nivel de organización son las parcialidades de anan y urin, en aquellas comunidades donde prevalece la bipartición. Se distinguen dos modalidades: uno, es el caso específico de Yanque, donde las parcialidades de Anan y de Urin realizan sus faenas festivas separadamente, con sus propias Comisiones de Regantes, en fechas distintas, por ser al mismo tiempo comunidades campesinas independientes, (Valderrama y Escalante, Op. cit.); dos, en las demás comunidades del valle, estén o no organizadas en parcialidades, el yarqa aspiy se realiza unitariamente, con una Comisión de Regantes centralizada, en una sola fecha e involucra a todos los comuneros y propietarios sin excepción. En ambos casos, los actos relativos a la fiesta del agua son funciones costumbristas de la Comisión de Regantes de cada comunidad campesina, a la que se adhieren otros cargos ceremoniales, según las particularidades de cada localidad.

Como ya se mencionó, cada Comisión de Regantes está conformada por: presidente, vicepresidente, secretario, tesorero, fiscal, vocales (2) y regidor de aguas. Si bien el presidente es la cabeza de la organización del riego, es el cargo de regidor de aguas, el que tiene en sus manos el poder y la autoridad en la distribución de las mitas del agua. el regidor de aguas o yaku alcalde, es la autoridad, entendido también por los comuneros usuarios como el "dueño" de las aguas con que riegan, por lo que debe ser respetado como tal y recibir de los demás miembros de la comunidad las consideraciones de su papel. Durante la festividad del agua, el yaku alcalde lleva el símbolo de la vara. Es el que preside y dirige las faenas en la limpieza de los canales y reservorios, así como de los actos ceremoniales en las nacientes de los manantiales y en los pagos a los dioses del agua en los lugares sagrados de cada comunidad campesina. El yaku alcalde es la principal figura en los ritos sagrados.

En lo concerniente a las faenas en los canales y reservorios, el yaku alcalde supervigila los trabajos y comparte funciones con los capitanes o jefes de cuadrillas en las que

27 Hay varias denominaciones: en la región central del Perú se le conoce como Champería o Fiesta del agua (Huarochirí), en el norte peruano lo llaman cequia piché o limpia cequia (Ancash).

28 En Raquia (Bolognesi) lo hacen en febrero, en Carampoma (Huarochirí) en marzo, en Huanza (Huarochirí) en junio, en Huanri (Ocros) en setiembre, en San Pedro de Casta (Huarochirí) en octubre, para citar algunas fechas del año. 
están organizados los usuarios. Para los fines ceremoniales de los pagos a los dioses es acompañado por el sacerdote andino ${ }^{29}$, que en quechua llaman Kamachikuq yana y el Rikuq. En algunas localidades, como en Canocota, estos actos ceremoniales son de carácter público, en otras lo realizan sólo con una pequeña comitiva presidida por el yaku alcalde. Con los usuarios del agua de riego se complementa la estructura de la organización del yarqa aspiy. Son usuarios todos los comuneros y propietarios no comuneros que tienen derechos a mitas del agua. En cada comunidad hay determinado número de usuarios registrados en el padrón de regantes que maneja el regidor de aguas. Todos ellos están obligados a asistir al yarqa aspiy para cumplir con las faenas de limpieza y reparación de canales y reservorios, tanto de los principales como de los canales y reservorios secundarios. Asimismo, cada usuario está obligado a cumplir con dos tipos de cargos en su comunidad: cargos civiles y cargos religiosos. Dentro de los cargos civiles están los de ser elegidos miembros de la organización comunal, miembro de la Comisión de Regantes y otros cargos que obligan los estatutos y reglamentos internos de cada comunidad. El cargo de yaku alcalde es uno de los cargos civiles. Los cargos religiosos consisten en pasar las fiestas devocionarias de los santos patronos, que son jerárquicos, de acuerdo a su importancia. Por lo anterior, el ser usuario de las aguas de riego en los pueblos del valle del Colca, no consiste sólo en reclamar su derecho a la mita del agua de riego y pagar el derecho correspondiente, va más allá: consiste en cumplir con una larga red de responsabilidades con la comunidad. En compensación recíproca, el comunero es usuario de varios recursos económicos, sociales y culturales, donde el derecho al riego es el más importante recurso que exige en su mundo local (Montoya, 1980; Fonseca, 1983; Castillo, 2007; Figallo, 2008, entre otros).

La faena. Es la parte laboral de la fiesta del agua. Para todos los usuarios significa una responsabilidad imprescindible: el de cumplir fielmente con los trabajos programados en la limpieza de los canales y reservorios principales y secundarios. Para los fines de la faena, los usuarios se organizan por parcialidades o en pequeños grupos de 10 a 15 comuneros, dirigidos por uno de ellos, según el orden establecido por la autoridad de riego. El primer día de la faena, la autoridad de riego da lectura de los nombres de los cabezas de grupos o cuadrillas y de la lista de comuneros que están bajo el mando de cada jefe. Esta designación rige para todos los días que dura el yarqa aspiy en cada población. Cuando comienza la faena de un canal, la autoridad de riego o la persona designada por él fija la extensión aproximada del canal que le toca limpiar a cada cuadrilla. Cada jefe de grupo, a su vez, distribuye el espacio que le toca a cada comunero y luego supervigila el trabajo de su grupo, cuidando que todos cumplan cabalmente con la limpieza. Durante el tiempo dedicado para la faena, la distribución de espacios para cada jefatura y luego para cada comunero se repite tantas veces como sea necesario, de acuerdo a la extensión del canal y de los días señalados para limpiarla. Cuando se trata de limpiar el lecho de los estanques, la distribución de los espacios para cada jefatura y para cada comunero se hace por cuadriláteros de extensión aproximada. Al concluir con la limpieza, la autoridad de riego ordena el descanso de los trabajadores y brinda aguardiente con ellos. En las localidades donde contratan bandas de músicos, los comuneros retornan al pueblo en algarabía popular, bailando al ritmo que los músicos interpretan. Por lo general, las faenas se hacen por las mañanas, dejando las tardes para los ritos costumbristas y el baile general. En cada pueblo están debidamente fijados los días dedicados a la faena, que van de tres a cinco días, según la tradición interna de cada pueblo. Durante el desarrollo de estas fiestas se depuran y actualizan los padrones de regantes, que aumentan o disminuyen en número, de acuerdo a la dinámica interna. Cada

29 Es el especialista en realizar el ritual del pago en los sitios sagrados. En cada comunidad hay personas mayores, con amplios conocimientos en estos actos, quienes ofician de "sacerdotes" en las yarqa aspiy. 
año, se presentan casos de salidas y de entrantes de usuarios. La autoridad del riego pasa lista diariamente en la plaza pública, de tal modo que cada usuario va formando grupo en la cuadrilla que le corresponde, como ocurre en Chivay y en Madrigal. En Canocota la formación de los usuarios en la plaza pública es muy estricta y militarizada. Cada comunero contesta su lista, lampa en mano se cuadra en la fila de su cuadrilla. La lampa simula al fusil. Cuando la autoridad ordena: ipresenten armas! Los comuneros en formación obedecen en la forma que lo hacen los militares.

En estos tiempos de migraciones campo-ciudad, son varios los que llegan a cumplir sus obligaciones de Arequipa, Lima y otros lugares del país y del extranjero. Se integran a sus grupos y parcialidades correspondientes y le dan mayor prestancia a la reparación de canales y reservorios, con sus aportes económicos, sus obsequios y sus participaciones personales en estos actos colectivos. En lo fundamental, los que han migrado prefieren no perder sus derechos al riego y a sus costumbres; es decir, no se desligan de la tierra que han heredado de sus ancestros. Muchos de ellos, ya no trabajan directamente sus parcelas, continúan produciendo recursos agrícolas apelando a distintos mecanismos: siembras a medias con terceros, préstamo de sus parcelas a familiares, arriendo a terceros. Por estos medios, el comunero o parcelero que ha migrado a otros lugares sigue usufructuando el derecho a la mita de agua, que es el valor complementario de las parcelas de su propiedad. Por otro lado, el sistema de cultivos al partir (a medias), le permite al migrante, continuar consumiendo los productos que se cultivan en la tierra de su localidad de origen. En muchos casos, la idea y la práctica de no desligarse de la tierra, le da buenos dividendos, que contribuyen a mejorar los ingresos familiares, cualquiera sea la residencia fijada por la familia. Para los comuneros del lugar y para los migrantes, el yarqa aspiy constituye no sólo un aspecto importante de sus identidades locales y regionales, es también un complemento económico de su condición de citadino.

Los rituales. El yarqa aspiy es en todo el territorio andino una fiesta colectiva que incluye en su estructura trabajo, ritos religiosos, música y danzas, comilonas, actos lúdicos y algarabía popular. Lo que varía de región en región y de pueblo a pueblo son las particularidades, de acuerdo a sus propias costumbres, la naturaleza de sus infraestructuras de riego y de las características de sus deidades regionales y locales. El yarqa aspiy del valle del Colca responde a las tradiciones agrarias de los pueblos del sur peruano. En su ejecución, la parte correspondiente a los rituales, es en realidad variada y abarca actos de distinto tipo, aplicados en distintos momentos de la fiesta: iniciación, bendición de las varas, enfloramiento de los sombreros, control de los usuarios en sus cuadrillas respectivas, las tinkadas, ofrenda a las deidades, banquetes, castigo simbólico a los que no cumplen con la costumbre, ofrenda a los funcionarios, reconocimiento de nuevos usuarios, despacho, cumplimiento con los músicos.

El funcionario principal del yarqa aspiy es, como ya hemos dicho, el Yaku Alcalde, que en algunas poblaciones lo llaman mayordomo. Lo acompañan los demás miembros de la Comisión de Regantes. Cada uno de ellos lleva una vara hecha de madera con incrustaciones de plata, que es el símbolo de autoridad, mando y al mismo tiempo representa al espíritu de los apus. Por esta simbología, la vara asume un carácter sagrado durante la fiesta, que todos los comuneros respetan y le rinden honores en distintos momentos. Cuando se inician los actos, los comuneros usuarios se reúnen en la casa del yaku alcalde o en el local de la Comisión de Regantes. Por lo general, esta reunión lo hacen por la noche, que se conoce como la noche del Velakuy o víspera de la festividad. Allí se realiza el ritual público del bautizo de las varas y prenden flores en los sombreros como símbolo de florecimiento. Durante todos los días que dura la fiesta, los sombreros de las autoridades del agua y de 
los usuarios se mantienen floridas. Hacen los primeros brindis con aguardiente, vino o chicha de jora en keros de madera, según la particularidad de cada comunidad. Instalan la mesa dedicada al culto del agua y a los apus montañas, prenden velas y reparten la coca para la primera tinkada, que consiste en consumir colectivamente la hoja sagrada alrededor de la mesa, con cal, cigarro sin filtro y aguardiente. La tinka dura toda la noche del velakuy, donde se sirve la cena y el infaltable café. La mesada de la víspera es similar en todas las poblaciones, incluye: hojas de coca, grasa de camélidos sudamericanos (untu), feto disecado de llama, preferentemente de vicuña (Sullu), mazorcas de maíz de colores (misa sara $)^{30}$, aguardiente o vino en botella, hojas de plantas aromáticas y en algunos casos botellas de agua del mar, metales preciosos y monedas de oro y plata. En unas poblaciones arman una sola mesa, en otras dos, una para los hombres y la otra para las mujeres.

Los envarados son cinco o seis en cada comunidad: el yaku alcalde y los principales miembros de la Comisión de Regantes. Las varas pueden ser propias o alquiladas de otros comuneros. En cualquiera de los casos, las varas son instrumentos de madera de palmera chonta, traída de la selva, que cada familia guarda desde tiempos antiguos, por eso son de propiedad familiar y no individual. Si la familia del yaku alcalde no dispone de una vara familiar tiene que alquilar de otra familia. Para legitimar su valor simbólico y su sacralidad tiene que ser bautizado cada año; pasa por un ritual especial a cargo del sacerdote andino, antes de ser entregado al funcionario de turno. En cada lugar donde llega la comitiva, ya sea en locales públicos, casas particulares o en el campo, las varas son colocadas en grupo en un lugar predeterminado. Cada comunero usuario hace la reverencia ante las varas en señal de pleitesía. En Canocota, los rituales del brindis comunal pasan por la participación de las varas de autoridades. Las varas son colocadas con la punta en un recipiente, de tal manera que cada comunero brinda primero con las varas, derramando una parte de la chicha o del aguardiente sobre las varas y luego bebe. Este ritual se repite en tantas paradas como se producen en el proceso de los trabajos. En el imaginario de los campesinos del valle, la vara representa a los dioses tutelares, a los apus montaña de donde nacen las aguas.

Hay en los pueblos del valle varios ritos dedicados a las deidades del agua. Uno de ellos es el dedicado al Mallku, que es el nombre sagrado del agua. En cada comunidad hay ritos especiales dedicados al mallku, ya sea en un solo acto o en ceremonias particulares para cada uno de los manantiales y montañas nevadas. Tomando como ejemplo el de Canocota, se establece que la ceremonia del pago al manantial principal del pueblo se realiza el primer día de los trabajos. Con este fin, las autoridades del agua y un grupo numeroso de comuneros y sus esposas se trasladan en la madrugada al cerro de donde brota el agua, acompañado de una banda de músicos. El sacerdote andino y sus ayudantes arman la mesa sagrada en un plano encima del manantial con todos los elementos de una mesa dedicada a los dioses: sullu, untu, coca quintu, misa sara, hojas aromáticas, cigarro sin filtro, chicha y otros complementos. Sahuman la mesa con humo, dicen un breve discurso de petición de que el agua se mantenga siempre brotante y luego queman los elementos rituales de la mesa y el sacerdote andino se acerca a la salida del manantial para esparcir las cenizas de lo quemado, diciendo frases que sólo él sabe su contenido. Las mujeres y varones que acompañan en la ceremonia arrojan pétalos de flores en el agua que brota del subsuelo, mientras bailan al ritmo de la música que interpreta la banda de músicos. Concluido con este ritual, las autoridades y sus acompañantes brindan licores y chicha y luego bailan chimaiches, wititis y huaynos en una explanada, aproximadamente por una hora, antes de retornar al pueblo para participar en el primer día de los trabajos de limpieza del primer canal.

30 En el valle del Colca llaman misa sara al maíz de dos o más colores, en los pueblos de Ancash llaman misha a la mazorca de maíz de colores al que consideran sagrada. 
En otras localidades como en Madrigal, Pinchollo, Cabanaconde y Yanque, los rituales del pago a los Apus (montañas nevadas o sin ellas) denominado Iranta están reservados para una comitiva selecta, presidida por el Yana o sacerdote andino ${ }^{31}$ y sus ayudantes, además de las personas elegidas previamente por los usuarios. Se dirigen a los cerros sagrados de donde nacen las aguas, como de Yanque Urinsaya que se dirigen al nevado Mismi o los de Pinchollo y Cabanaconde que viajan hacia el nevado Hualca Hualca, para preparar allí las mesas con los elementos ya conocidos y ofrecerlos humildemente a sus dioses montaña, en agradecimiento por proveerles de agua todo el tiempo y rogándoles que estas aguas no se sequen. Las comitivas que suben a las montañas a realizar el pago a los dioses montaña se quedan en algunos casos por varios días, haciendo repetidas ceremonias con las mesadas, en una actitud de ofrecerles sendos "banquetes" a las deidades con las "comidas" que les gusta. Utilizando los elementos principales de la mesa, el yana y sus ayudantes forman pequeñas unidades de "comida", en la que el untu, el sullu, las hojas de coca quintu y otros elementos constituyen unidades individualizadas para cada una de las deidades, con cantidades predeterminadas de elementos, dedicados a cada uno de los dioses principales y secundarios de cada localidad, que Valderrama y Escalante, precisan en su trabajo (1988: 111-112) para el caso de Yanque Urinsaya y Yanque Anansaya. Está en la mentalidad de los campesinos del valle la idea de que las deidades esperan su banquete particular, además del banquete común, en los términos que están establecidos por la tradición. Durante el pasado prehispánico, cuando se producían varios años de sequías, la lógica ideológica consistía en entender que los dioses esperaban de los hombres mayores sacrificios. Este era el momento adecuado para realizar la Capacocha, ceremonia especialísima en la que se ofrecía a los Apu montañas el cuerpo inmaculado de una niña de especial belleza, escogida en la región para el "pago" ceremonial de reciprocidad. No hay duda de que la "momia Juanita", encontrada en los deshielos del nevado Ampato, cerca del Hualca Hualca, fue una entrega ceremonial a los "dueños del agua" de aquel tiempo. Más de quinientos años después, ya no sacrifican cuerpos humanos, pero siguen ofreciendo "banquetes" en ceremonias muy bien organizadas, tanto en las mismas poblaciones, como en las montañas sagradas y en las principales nacientes de los manantiales de cada comunidad (Valderrama y Escalante, 1988; Fernández, 1997).

Son igualmente significativas las ceremonias del "despacho", que se realizan al finalizar las fiestas del agua en los pueblos del valle. Se entiende por despacho al acto de despedir y agradecer jubilosamente a los que han cumplido fielmente con realizar la costumbre que el pueblo les ha encomendado. Estos actos están referidos a los funcionarios y a los músicos de la fiesta. Por eso se realizan durante el último día del yarqa aspiy de cada localidad, en similitud a lo que hacen con los funcionarios de fiestas patronales. Por tradición, el último día de la fiesta, los músicos interpretan aires alegres de despedida que al mismo tiempo expresan algo de tristeza porque el reencuentro de las familias del pueblo llega a su fin. El yaku alcalde y su esposa, siempre acompañados de los otros miembros de la Comisión de Regantes, salen bailando música corrida, enlazados de las manos o abrazados en forma de medias rondas, para luego detenerse en los patios o en la plaza para brindar licor con sus conciudadanos que han participado en la limpia acequia. Es durante estos recorridos de alegría-tristeza cuando los familiares, amigos y público, se acercan a ellos para obsequiarles huahuas de pan, bebidas alcohólicas, billetes en soles o dólares, como gesto de solidaridad y reciprocidad. La entrega de las huahuas son los más espectaculares

31 Los sacerdotes de la religión prehispánica han prevalecido al tiempo y subsisten en los Andes con distintos nombres: "alto misayoj", "brujo", "curioso", "entendido", etc. Los colonizadores los denostaron llamándoles: dogmatizadores, hechiceros, brujos, demonios, apóstatas, etc. 
obsequios al Yaku Alcalde y a su esposa. Son panes gigantes en forma de corazón de más o menos30 a $40 \mathrm{~cm}$ de largo y $25 \mathrm{~cm}$ de ancho, hechos de harina de trigo, que simulan figuras humanas, que son colgados al pecho y a la espalda de la pareja del funcionario. Ellos están preparados para recibir este tipo de regalos, por lo que llevan una manta de colores a la bandolera, donde van colocando las huahuas, unas sobre otras. Son tantos los obsequios de huahuas que la familia tiene que ir descargándolo, a fin de abrir espacio para nuevos regalos. Los músicos siguen tocando distintas piezas musicales, correspondiente al despacho mientras la gente baila formando rondas y los oferentes siguen colgando huahuas en señal de cariño y fraternidad comunal. Muchos de ellos recibieron del Yaku Alcalde huahuas cuando él cumplía esa responsabilidad, otros lo hacen ahora porque recibirán huahuas cuando asuman ese cargo: ese es el sentido de los gestos de reciprocidad que funciona con las huahuas, en todas las localidades del valle, tanto en las fiestas patronales, en las faenas festivas de la siembra colectiva de chacras de santos, como en el tradicional yarqa aspiy, fiesta del agua o escarbe de acequias.

No sólo de huahuas se beneficia el yaku alcalde o mayordomo y su esposa, recibe igualmente cajas de cerveza, cántaros de chicha, colaboraciones con víveres, pago del costo de las bandas, etc. Estas contribuciones se consumen en la plaza pública, con la participación masiva de los comuneros y visitantes. Mientras bailan jubilosamente, brindan con la cerveza acumulada por cajas y con la chicha que llega por cántaros. En estos actos del despacho nadie es espectador, todos participan en el intercambio de dones, de brindis, de fraternidad y de alegría generalizada. Los actos de solidaridad y reciprocidad que se intercambian durante la finalización de la fiesta del agua son los ingredientes más significativos del yarqa aspiy en el valle del Colca; son solidarios en el trabajo, solidarios en el cumplimiento de los cargos públicos y solidarios en otros eventos sociales del calendario festivo de cada pueblo. Los músicos reciben lo suyo. Cada uno de sus integrantes recibe huahuas, frutas y productos agrícolas en crudo, adheridas en pitas, que le cuelgan a la bandolera. Cuando salen por las calles y la plaza acompañando al funcionario, los músicos ya están con sus "fiambres" sobre la espalda, en señal de despedida. De este modo, la fiesta del agua concluye con mucha algarabía popular y con particulares demostraciones de solidaridad, cuyo patrimonio se extiende a casi todo el mundo andino.

\section{Conclusiones}

1. El valle del Colca es un espacio andino con 23000 habitantes, con 6300 propietarios de tierras cultivables, agrupados en dieciséis poblaciones, dedicadas básicamente a la actividad agrícola y ganadera, orientada a cubrir el autoconsumo y el intercambio de productos con el mercado regional. Por haberse convertido en una región eminentemente turística, por exhibir el cañón más profundo del planeta, ser hábitat de cóndores andinos y estar cubierto de un paisaje de andenes, el turismo es una actividad nueva que beneficia a un sector importante de la población y es atracción de inversionistas a favor de la industria sin chimenea.

2. Desde tiempos prehispánicos, la agricultura y la ganadería han constituido la base económica de los habitantes de la región. En las poblaciones altoandinas de Tuti, Callali, Sibayo y Tisco, prevalece hoy como antaño, la cría extensiva de camélidos sudamericanos (llamas y alpacas) y de ovinos, para comercializar lana, cuero y carne a las ciudades, centros mineros de la región y la exportación al exterior, a través de intermediarios. En las zonas intermedias, desde Canocota y Tuti por el este hasta Cabanaconde, Tapay y Huambo por el oeste, la agricultura es la actividad básica de la economía campesina, que se complementa con la crianza de ganado vacuno, ovino y 
caprino. Por su importancia, casi el $80 \%$ de las tierras agrícolas, calculadas en cerca de 10000 hectáreas, están dedicadas al cultivo de alfalfa, orégano, papa, haba, arveja, trigo, cebada, maíz. Otros cultivos como avena, quinua, kiwicha, olluco, oca, mashua, frutales y verduras cubren el $20 \%$ restante de tierras. Algunos de estos productos como el orégano, las habas verdes y secas, maíz en choclo y en granos, papa en sus variedades principales, se comercializan hacia Arequipa.

3. Implementar la agricultura en el valle ha sido históricamente un logro heroico de los antiguos habitantes. La accidentada geografía y la imposibilidad de utilizar las aguas del río Colca, por la profundidad de su cauce, han sido resueltos por los agricultores originarios y modernos con extraordinario ingenio. Para aumentar espacios agrícolas a sus pocas tierras planas y semiplanas, han construido andenes para cultivar en una especie de maceteros. Las tierras de los pueblos del valle, desde Coporaque hasta Cabanaconde, muestran hoy un vistoso paisaje cultural de la ingeniería agrícola, hecha por los antiguos collaguas, cabanas y por los incas. Por estos logros tempranos de la ampliación de frontera agrícola, la producción de recursos de consumo autoabastece a la región y ha creado excedentes para cubrir los tributos coloniales y republicanos, así como para la comercialización. Las herramientas de origen prehispánico como la chaquitaklla y la azada siguen siendo los más usadas para trabajar en los terraplenes y terrenos declives, junto con la barreta, la lampa y la yunta de bueyes y equinos. El tractor ha llegado para roturar en terrenos planos.

4. Sin la ingeniería hidráulica construida en toda la cuenca para asistir de riego a los cultivos, la agricultura no hubiera tenido el éxito que tiene. Desde antes de la presencia de collaguas y cabanas hasta el dominio de los incas, la construcción de múltiples canales para conducir las aguas hasta las campos de cultivo y de reservorios para almacenar la siempre escasa agua disponible ha sido la mejor política agraria practicada por los grupos humanos que han habitado históricamente este valle. Hay en los pueblos de la cuenca, 103 fuentes de agua, 62 canales principales, 74 reservorios. A esta infraestructura se agregan las 26 válvulas del canal que conducen las aguas del reservorio de Condoroma a los arenales de Sihuas, de la que se benefician las comunidades de la margen izquierda. Muchos canales y reservorios están siendo revestidos de cemento para aprovechar mejor el riego; también hay varios proyectos de represamiento de lagunas naturales para aumentar el caudal hídrico. Con estos aportes de mejoramiento, fomentados por las ONG y agencias del gobierno, la agricultura de riego se desarrolla positivamente.

5. La permanente escasez de agua para el riego ha desarrollado desde la época prehispánica una ideología de sacralización de la naturaleza, bajo el ideal de mantener equilibrio entre el hombre y las deidades de su entorno. Los agricultores del valle del Colca no han olvidado la tradición ni la fe en sus dioses montaña, lluvia, truenos, agua y camaquenes, que son "los que propician" la abundancia de la lluvia, por tanto del flujo permanente del agua. Para estar en buenas relaciones con sus deidades propiciatorias del recurso hídrico y con la madre tierra que da sus frutos, ha construido desde antiguo ceremonias y rituales dedicados a los dioses de la naturaleza. La costumbre de reparar canales y reservorios en el calendario anual de las comunidades campesinas sirve también para realizar los "pagos" a los apus montaña Mismi, Hualca Hualca, de sus manantiales, sus gentiles, para agradecerles por sus bondades y pedirles que llueva y haya agua permanente. En estos rituales denominados yarqa aspiy, son los yaku alcaldes o regidores de agua, los que presiden las ceremonias y los trabajos, con la participación obligatoria de los comuneros usuarios. La agricultura de riego en el valle del Colca se complementa con este complejo sistema de ritos religiosos que aún prevalece en el tiempo. 


\section{Bibliografía}

ALEGRÍA, Julio

2008 “La gestión del agua en el Perú: antecedentes, situación y perspectivas”, en: Hilda Araujo Los Andes y las poblaciones altoandinas en la agenda de la regionalización y la descentralización, CONCYTEC, Lima.

ARGUEDAS, José María

1964 "Puquio, una cultura en proceso de cambio", en Luis E. Valcárcel Estudios sobre la cultura actual del Perú, UNMSM, Lima.

ARAUJO CAMACHO, Hilda (Editora)

2008 Los Andes y las poblaciones altoandinas en la agenda de la regionalización y la descentralización, CONCYTEC, Lima.

ARROYO AGUILAR, Sabino

2008 Culto a los hermanos Cristo. Sistema religioso andino y cristiano: redes y formas culturales del poder en los Andes, Fondo Editorial de la Fac. de CC. SS, UNMSM, Lima.

BONILLA MAYTA, Heraclio

1987 “Comunidades indígenas y Estado Nación en el Perú", en Comunidades campesinas: cambios y permanencias”, Centro de Estudios Sociales Solidaridad (Chiclayo) y CONCYTEC, Lima.

BOURLIAUD, Jean y otros

1988 Chakitaklla: estrategia de barbecho e intensificación de la agricultura andina, ORSTOM - PISA, Lima.

CARRIÓN CACHOT, Rebeca

2005 El culto al agua en el antiguo Perú, Instituto Nacional de Cultura, Lima. (Primera edición, 1955)

CEPAL

2007 Panorama social de América Latina 2006, Santiago de Chile.

COCK, Guillermo

1977 “Los kurakas de los collaguas: poder político y poder económico”, en: Historia y Cultura, $\mathrm{N}^{\mathrm{o}} 11$, Lima.

DEL AGUILA, Levy

2008 "Cuencas y complejidad en el ordenamiento del espacio nacional", en: Hilda Araujo, Los Andes y las poblaciones altoandinas en la agenda de la regionalización y la descentralización, CONCYTEC, Lima.

\section{DESCO}

1985 Alpaqueros de Caylloma: problemas y alternativas, Comisión Organizadora de Criadores de Alpacas en la provincia de Caylloma, Lima.

DUVERGER, Christian

1996 La conversión de los indios de Nueva España, Fondo de Cultura Económica, México.

DUVIOLS, Pierre

1973 "Huari y llacuaz: agricultores y pastores. Un dualismo pre-hispánico de oposición y complementariedad", Revista Museo Nacional, vol. XXXIX, Lima, 1973.

EARLS, John

2008 "Manejo de cuencas en cambio climático", en: Hilda Araujo, Los Andes y las poblaciones altoandinas en la agenda de la regionalización y la descentralización, CONCYTEC, Lima. 
ESPINOZA SORIANO, Waldemar

1987 Los incas. Economía, sociedad y Estado en la era del Tahuantinsuyo, Amaru editores, Lima.

FARFÁN, Carlos

2002 "El simbolismo en torno al agua en la comunidad de Huaros-Canta, en: Bulletin de'l Institut Français d' Études Andines, IFEA, Lima.

FERNÁNDEZ JUÁREZ, Gerardo

1997 Entre la repugnancia y la seducción: ofrendas complejas en los Andes del Sur, Centro de Estudios Regionales Andinos "Bartolomé de las Casas", Cusco.

FIGALLO ADRIANZÉN, Guillermo

2007 Origen, exclusión y reafirmación de las comunidades campesinas del Perú, Editorial San Marcos, Lima.

FONSECA MARTEL, César

1983 "El control comunal del agua en la cuenca del río Cañete", en: Allpanchis $N^{\circ} 22$, Lima.

FUENZALIDA VOLLMAR, Fernando

1977 "Santiago y el Wamani: aspectos de un culto pagano en Moya", en Debates en Antropología, № 5, PUCP, Lima.

GELLES, Paul

1986 "Sociedades hidráulicas en los Andes: algunas perspectivas desde Huarochirí", en Allpanchis $\mathrm{N}^{\mathrm{o}} 27$, Instituto Pastoral Andino, Cusco. № 27.

GOLTE, Jürgen

1980 La racionalidad de la organización andina”, Instituto de Estudios Peruanos, Lima.

GRUPO PERMANENTE DE ESTUDIO SOBRE RIEGO

1993 Gestión del agua y crisis institucional, ITDG-SNV, Lima.

HENDRICKS, Jan

1969 "Distribución de aguas en sistemas de riego", en Allpanchis No 28, Lima.

HOLDRIDGE, Leslie R.

1967 Life zone ecology, Tropical Science Center, San José de Costa Rica.

INSTITUTO NACIONAL DE ESTADÍSTICA E INFORMÁTICA.

Censos Nacionales: 1940, 1961, 1972, 1981, 1993 y 2007, Instituto Nacional de Estadística e Informática, Lima.

JIMENEZ DE LA ESPADA, Marcos

1885 Relaciones geográficas de Indias, Ministerio de Fomento-Perú, Tipografía de Manuel G. Hernández, Madrid.

JUNTA DE USUARIOS VALLE DEL COLCA

2005 Plan estratégico 2005-2015, documento de trabajo, Chivay, Arequipa. Diagnóstico de la Junta de Usuarios Valle del Colca, documento de trabajo, Chivay, Arequipa.

LLANOS, Oliverio y OSTERLING, Jorge

1986 "Ritual de la fiesta del agua en San Pedro de Casta, Perú", en Journal of Latin American Lore, Los Ángeles, California, USA.

LLOSA, H. y BENAVIDES, María A.

1994 "Arquitectura y vivienda campesina en tres pueblos andinos: Yanque, Lari y Coporaque en el valle del río Colca; Arequipa", en: Bulletín, tomo 23, № 1, IFEA, Lima.

MÁLAGA MEDINA, Alejandro

1977 "Los collaguas en la historia de Arequipa en el siglo XVI", en: Collaguas, Pontificia Universidad Católica del Perú, Lima. 
MANRIQUE, Nelson

1985 Colonialismo y pobreza campesina: Caylloma y el valle del Colca. Siglos XVI$X X$, DESCO, Lima.

MASSON M., Luis

1986 "Rehabilitación de andenes en la comunidad San Pedro de Casta, Lima", en: Carlos de la Torre y Manuel Burga, Andenes y camellones en el Perú: Historia, presente y fututo, CONCYTEC, Lima.

MATOS MAR, José y MEJÍA, José Manuel

1980 La reforma agraria en el Perú, Instituto de Estudios Peruanos, Lima.

MAYER, Enrique

2004 Casa, chacra y dinero: economía doméstica y ecología en los Andes, Instituto de Estudios Peruanos, Lima.

MILLONES, Luis y ONUKI, Yoshio

1994 El mundo ceremonial andino, Editorial Horizonte, Lima.

MONTOYA ROJAS, Rodrigo

1989 Lucha por la tierra, reformas agrarias y capitalismo en el Perú del siglo XX, Mosca Azul Editores, Lima.

MORLON, Pierre

1996 Comprender la agricultura campesina en los Andes Centrales: Perú-Bolivia, Centro de Estudios Regionales Andinos "Bartolomé de las Casas", Cusco.

MORLON, P., ORLOVE, J. y A. HEBON

1982 Tecnologías agrícolas en los Andes Centrales: perspectivas para el desarrollo, COFIDE, Lima.

MURRA, John V.

1972 "El control vertical de un máximo de pisos ecológicos en la economía de las sociedades andinas", en Íñigo Ortiz de Zúñiga Visita de la provincia de León de Huánuco (1562), tomo II, Universidad Hermilio Valdizán, Huánuco.

1975 Formaciones económicas y políticas del mundo andino, Instituto de Estudios Peruanos, Lima.

NEIRA, Máximo

1961 Los collaguas, tesis doctoral, Facultad de Letras, Universidad Nacional San Agustín de Arequipa, Arequipa.

ONERN

1973 Inventario, evaluación y uso nacional de los recursos naturales de la costa. Cuenca del río Camaná-Majes, Lima.

PEASE G., Franklin (Comp.)

1977 Collaguas I, Pontificia Universidad Católica del Perú, Lima.

PORTOCARRERO, Javier (editor)

1986 Andenería, conservación de suelos y desarrollo rural en los Andes peruanos, Asociación Naturaleza, Ciencia y Tecnología, Lima.

PULGAR VIDAL, Javier

1996 Geografía del Perú. Las ocho regiones naturales del Perú, Editorial Peisa, Bogotá, (Primera versión a mimeógrafo, UNMSM, Lima, 1960).

RÁEZ RETAMOZO, Manuel

2002 En los dominios del cóndor. Fiestas y música tradicional en el valle del Colca, Centro de Etnomusicología andina, Pontificia Universidad Católica del Perú, Lima. 
REGAL MATIENZO, Alberto

2005 Los trabajos hidráulicos del inca en el antiguo Perú, Instituto Nacional de Cultura, Lima. (Primera edición: 1970)

ROBLES MENDOZA, Román

2005 "Las iglesias andinas: huellas de la cristianización y religiosidad popular", en: Revista de Antropología $N^{o}$ 3, UNMSM, Lima.

TELLO, Julio C. y MIRANDA, Próspero

1923 "Wallallo, ceremonias gentilicias realizadas en la región cisandina del Perú" central, en Revista Inca, Vol. I, No 2, Lima.

TREACY, John M.

1994 Las chacras de Coporaque. Andenería y riego en el valle del Colca, Instituto de Estudios Peruanos (IEP), Lima.

TORD, Luis E.

1983 Templos coloniales de Colca, Arequipa, Atlas, Lima.

TORRE, Carlos de la y BURGA, Manuel (Editores)

1986 Andenes y camellones en el Perú andino: historia presente y futuro, Consejo Nacional de Ciencia y Tecnología (CONCYTEC), Lima.

TOSSI, Joseph A.

1960 Zonas de vida natural en el Perú: memoria explicativa sobre el mapa ecológico del Perú, Instituto Interamericano de Ciencia Agrícola de la OEA, Zona Andina, Boletín Técnico $\mathrm{N}^{\mathrm{o}} 5$.

TROLL, Carl

1945 "Las culturas superiores andinas y el medio geográfico", en Revista de la Universidad de Arequipa, Arequipa. La versión original de este artículo, escrita en alemán, se publicó en Berlín el año 1931.

ULLOA MOGOLLÓN, Joan de

1965 "Relación de la provincia de los Collaguas para la discrepción de las Yndias que su Magestad manda hacer" (1586), en Marcos Jiménez de la Espada, Relaciones geográficas de Indias-Perú, Vol. II, Ministerio de Fomento-Perú, Madrid, 1885.

VALDERRAMA, Ricardo y ESCALANTE, Carmen

1988 Del Tata Mallku a la Mama Pacha. Riego, sociedad y ritos en los Andes peruanos, Centro de Estudios y Promoción del Desarrollo (DESCO), Lima.

VARGAS SALGADO, Humberto

2005 El ritual de la champería y la economía campesina en los Andes peruanos: Laraos y otras comunidades de Huarochiri norte, UNMSM, Lima (Tesis doctoral).

VÁSQUEZ DE ESPINOZA, Antonio

1948 Compendio y descripción de las Indias Occidentales, Smithsonian Institution, Washington.

WACHTEL, Nathan

1976 Los vencidos. Los indios del Perú frente a la conquista española: 1530-1570, Alianza editorial, Madrid. 